\title{
Polyethylene Composites with Lignocellulosic Material
}

\author{
Emanuel M. Fernandes ${ }^{1,2, *}$, João F. Mano ${ }^{1,2}$, Rui L. Reis ${ }^{1,2}$ \\ ${ }^{1}$ 3B's Research Group - Biomaterials, Biodegradables and Biomimetics, \\ University of Minho, Headquarters of the European Institute of Excellence on \\ Tissue Engineering and Regenerative Medicine, Taipas, Guimarães, Portugal \\ ${ }^{2}$ ICVS/3B's - PT Government Associate Laboratory, Braga/Guimarães, Portugal
}

\begin{abstract}
The aim of this chapter is to describe in detail the advances in polyethylene reinforced with lignocellulosic material. Indeed, the successful employment of natural based materials to reinforce/improve the properties of polyolefins has been growing in a wide range of applications. Firstly, basic concepts and terminology adopted in the lignocellulosic composite materials are reviewed. The objective is to bring the reader's attention to important issues that must to be taken into account when working in this subject as well as by providing the most appropriate references for those with interest to delve into the topic. In the context of polyethylenelignocellulosic composites, ongoing research is then summarised mainly focussing on (i) the main aspects related to the selection of the commonly used lignocellulosic materials and the potential of its main chemical constituents, (ii) the principal methods used for the improvement of interfacial adhesion and (iii) the main adopted processing routes and the composite properties. Finally, applications, new challenges and opportunities of these polyethylene-lignocellulosic composites are also discussed.
\end{abstract}

Keywords:

${ }^{*}$ Corresponding author: Emanuel M. Fernandes (efernandes@dep.uminho.pt)

Visakh P. M and María José Martínez Morlanes (eds.) Polyethylene-Based Blends, Composites and Nanocomposites, (117-162) @ 2015 Scrivener Publishing LLC 


\subsection{Introduction}

Composites are a class of materials that comprises at least two or more distinct components that leads to a better material due to meaningful differences between components, in terms of physical and/or chemical properties. Nature has produced a huge number of natural fibres with high potential to reinforce the properties in many composites. More specifically, the thermoplastic composites containing organic material from renewable resources such as lignocellulosic fibres have become a viable alternative to inorganic fillers and synthetic fibres. Environmental benefits, good mechanical properties, low density, production costs and more easily recyclable are the main factors for the increased interest and widespread use [1-3]. Indeed, the combination of properties of both lignocellulosic materials and thermoplastics opened a new range of applications. One of those applications is related to the employment of polyethylene-lignocellulosic composites in the decking and construction, which has been a growing market over the past decades. Moreover, with the increasing pressure in issues related to environment and sustainable development, polyethylene-lignocellulosic composites have the potential to step into new markets. This would have a double benefit: (i) increase the production of the lignocellulosic materials and, as consequence, (ii) acquire new knowledge about the effective behaviour of these materials. The aim of this chapter is to describe in detail the advances in polyethylene reinforced with lignocellulosic material. Firstly, basic concepts and terminology adopted in the lignocellulosic composites and the properties of the lignocellulosic materials are reviewed. Lignocellulosic materials are basically constituted of cellulose, lignin and hemicellulose and in some species suberin $[2,4]$. In the form of natural fibres, they are distinct from synthetic fibres. For the case of polyolefin-lignocellulosic composites the main problem is that natural fibres are highly heterogeneous materials both physically and chemically $[5,6]$. The hydroxyl groups prevailing on natural fibres make them hydrophilic, but on the other hand, polyolefin matrices are also hydrophobic and therefore, natural fibre-polymer composites show typically poor interfaces. Nevertheless, better wetting and chemical bonding between fibre and matrix can improve the interface behaviour for different desirable levels of performance [5, 7-9]. Actually, successful strategies were developed to improve the interface and biodegradation resistance on polyethylene-lignocellulosic composites. In this context, the most investigated matrices are polyolefins, whilst the adhesion promoters are also mainly based on the same polyolefins but modified with maleic anhydride [10-12]. The chapter addresses the main strategies used to improve polyethylene-lignocellulosic composites interface. Then, the principal melt-based processes to obtain these polyethylene composites and their 
properties are described, with particular emphasis on the extrusion process. Afterwards, the potential of the main chemical lignocellulosic constituents obtained from renewable biomass feedstock is briefly reviewed, manly those with potential to replace some inorganic filler by improving the polyethylene composites and nanocomposites. Finally, the market applications, the main remarks and some future challenges in the area of polyethylene-lignocellulosic composites enclose this chapter.

\subsection{Materials}

\subsubsection{Polyolefins}

Polyolefins like polyethylene (PE) are commonly used polymers with wide range of applications. They are normally defined as polymers based on alkene-1 monomers or a-olefins and currently, they are the most widely used group of thermoplastic polymers. Based on their monomeric units and their chain structures, they can be divided into the following subgroups [13]: Ethylene - based materials - polyethylenes (PEs) - shows a predominantly linear chain structure. This group includes high density PE (HDPE), medium density PE (MDPE), linear-low density PE (LLDPE) and other varieties, which are distinguished through the regulation of density and subsequently mechanical properties through the incorporation of higher a-olefins (mostly butene, hexene and octene) as comonomers. Polyethylene is conventionally synthesized by following either low-pressure or high-pressure polymerization, from which the derived products are clearly distinguished. Polymerization at high pressure leads to branched chains and the polymer has a low density $0.915-0.935$ g. $\mathrm{cm}^{-3}$ with crystallinity between $40 \%$ and $50 \%$. On the other hand, when ethylene is polymerized at low pressure, the chain branching is eliminated. The resulting material has a crystallinity of $60 \%-80 \%$ and a density of $0.95-0.965$ g.cm ${ }^{-3}[14]$. The density and modulus of polyethylene increase with crystallinity. The repeat structure of $\mathrm{PE}$ is written as $\left(-\mathrm{CH}_{2} \mathrm{CH}_{2}-\right)_{n}$. The properties of PE depend on: molecular weight, molecular weight distribution, as well as on the degree and type of branching [15]. Polyethylene, like polypropylene, has many attractive properties, which make it a prime material for a number of applications. By this reason, the composites of polyethylene are continuously studied towards the increase of the number of applications. Polyolefins such as polyethylene, is one of the preferred choices among the commercial polymers because of their excellent combination of chemical and physical properties along with the low cost, superior processability and good recyclability [16]. For instance, high-density polyethylene (HDPE) exhibits good thermal stability, water vapour 
barrier (nonpolar), low glass transition temperature and high crystallinity, which make it suitable for instance in packaging frozen foods. In addition, polyethylene is not is not attacked by most acids, bases, or solvents and presents relatively high resistance to oxidation compared with polypropylene, hence, requires less amount of antioxidants for outdoor applications [14, 17]. When burned completely, it converts to carbon dioxide and water vapour.

\subsubsection{Recycled Polyolefins}

Recycled and waste thermoplastics are some of the major components of global municipal solid waste (MSW) and they present a promising raw material source for lignocellulosic composites, especially because of the large volume and low cost of these materials [18]. High density polyethylene (HDPE), low density polyethylene (LDPE/LLDPE), polypropylene (PP), Polyethylene terephthalate (PET), polystyrene (PS) and polyvinyl chloride (PVC) are the primary constituents of plastics in MSW. Reutilizing the post-consumed polymeric materials reduces the environmental impact and the consumption of virgin plastics [19]. Regarding the reuse of polyethylene, considerably research has been conducted in the area of the polyethylene-lignocellulosic composites materials [12, 19-24].

\subsubsection{Natural Fibres}

Lignocellulosic fibres, natural fibres or bio-fibres offers several advantages over the traditional ones. The most important are low density and low cost, good specific strength properties, nonabrasive during processing, $\mathrm{CO}_{2}$ neutral when burned and biodegradability $[5,25,26]$. Natural fibres are quite different from the synthetic fibres such as E-glass, carbon, aramid fibres among others. Natural fibres often consists of a bundle of elementary fibres, which results in an irregular shape depending on the number of elementary fibres and the way in which they are packed together [27]. Depending on the natural origin there are six basic types of natural fibres. They are classified as follows: bast fibres (jute, flax, hemp, ramie and kenaf), leaf fibres (abaca, sisal, agave and pineapple), seed fibres (coir, cotton and kapok), fruit (coir and oil palm), grass and reed fibres (wheat, bamboo, corn and rice) and all other types (wood, and roots) $[28,29]$. Depending on the natural fibre, the major chemical components are cellulose, hemicellulose, lignin, suberin.

Pectin, pigments and extra ctives can be found in lower quantities. For this reason, natural fibres are also referred to as cellulosic or lignocellulosic fibres $[28,31,33]$

Table 5.1 shows the chemical composition and the mechanical properties of several natural fibres under tensile load as compared with the synthetic E-glass fibres. 
Polyethylene Composites with Lignocellulosic Material

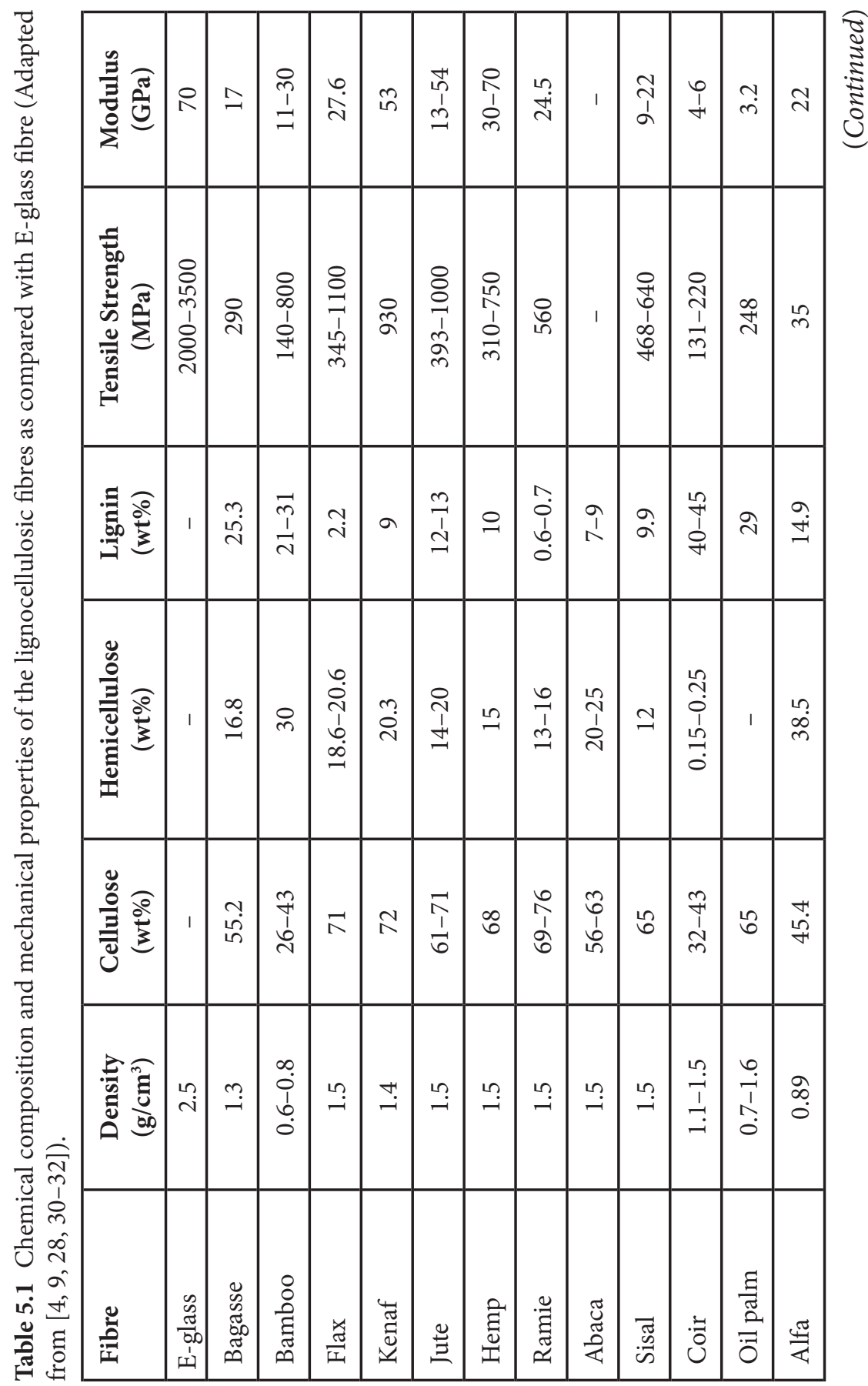




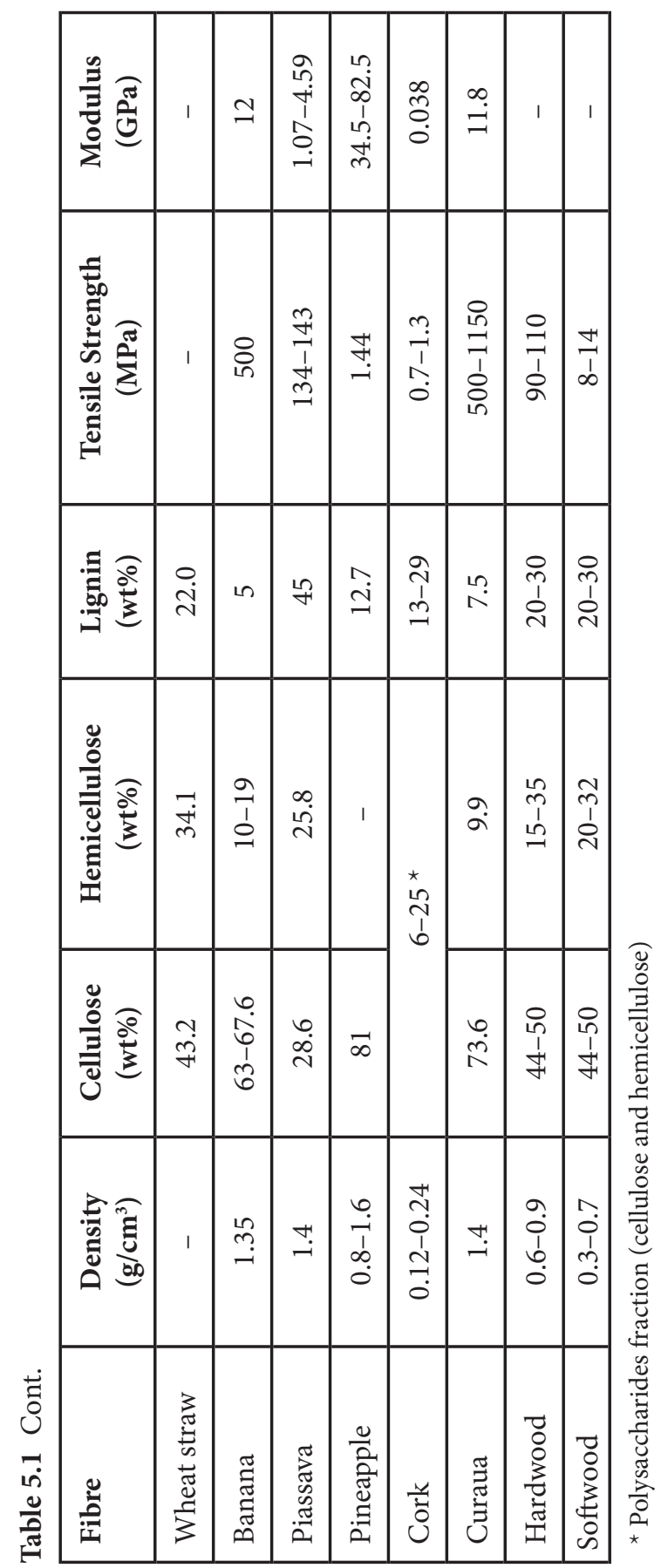


There is also a general interest in the sustainable production of chemicals and/or materials from renewable biomass feedstock. Indeed, they are regarded as promising materials that could replace petrochemical based polymers, reduce global dependence on fossil fuel sources and provide simplified end-of-life disposal [34]. The major chemical constituents derived from low-value biomass (i.e. lignocellulosic source) with potential to combine with polyolefins are: cellulose, hemicelluloses, lignin and suberin.

- Cellulose is the most abundant renewable natural biopolymer on earth and is a promising feedstock for the production of chemicals for their applications in various industries [35, 36]. This main structural constituent of plants is important, since it is seen as a renewable chemical resource to replace petroleum-based materials. Cellulose is a hydrophilic glucan polymer of D-glucopyranose units, which are linked together by $\beta$-(1-4)-glycosidic bonds [37]. Figure 5.1 shows the complex hierarchical structures that can be observed from the cellulose sources to the cellulose molecules. In plants, cellulose is arranged as a system of fibrils embedded in a lignin

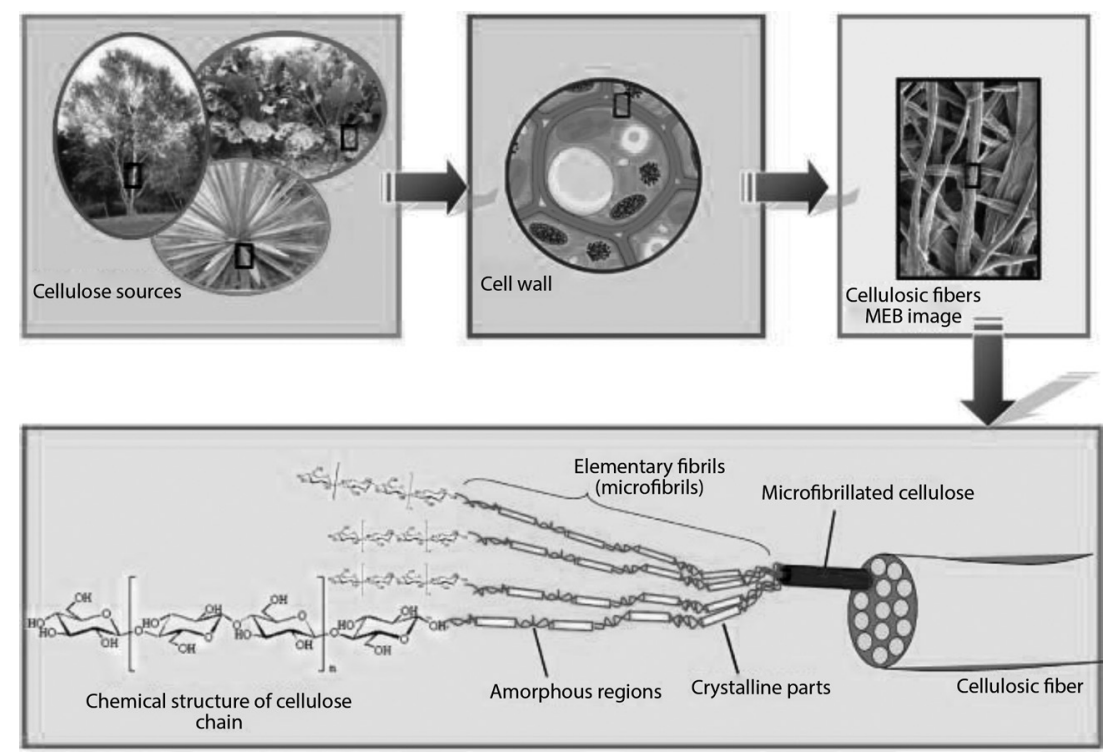

Figure 5.1 From the cellulose sources to the cellulose molecules: details of the cellulosic fibre structure with emphasis on the cellulose microfibrils. Reprinted with permission from Ref [39]. 
matrix. The microfibrils are a few nanometers of diameter presenting highly ordered regions (i.e., crystalline phases) alternated with disordered domains (i.e., amorphous phases) $[6,37]$. A single fibril has a diameter of $c a 5 \mathrm{~nm}$ and a length up to tens of micrometers [37]. These fibrils are comprised of different hierarchical microstructures commonly known as nano-sized microfibrils with high structural strength and stiffness, being the elongated crystalline rod-like nanoparticles designated by nanowhiskers. The Young's modulus of cellulose whiskers was determined by different authors to be between $110 \mathrm{GPa}$ and $250 \mathrm{GPa}$, that is close to the modulus of the perfect crystal of native cellulose and in the range of a Kevlar fibre (i.e. 124-130 GPa) [33, 38]. The experimental strength was assessed to be $10 \mathrm{GPa}$.

The potential of these nano-sized structures can be found in different areas of application [33, 37, 38, 40-43]. They are briefly referred as potential reinforcement in polyethylene, since the focus in this chapter is on the potential of different lignocellusic materials produced from natural fibres or agricultural/forest crops or residues.

- The hemicellulosic and pectic materials play an important role in fibre bundle integration and fibre bundle strength and individual fibre strength. Hemicellulosic polymers are branched, fully amorphous, and have a significantly lower molecular weight than cellulose. Because of its opened structure containing many hydroxyl and acetyl groups, hemicellulose is partly soluble in water and hygroscopic [44]. Cellulose and hemicelluloses contain free hydroxyl groups that confer to the wood its inherent hygroscopic character [6].

- Lignin is totally amorphous and hydrophobic in nature. It is the compound that gives rigidity to the plants. Lignin has a phenolic-based chemical structure; its high carbon and low hydrogen content suggests that it has a highly unsaturated and aromatic character. Lignin is characterized by its hydroxyl and methoxy groups [25]. The main difficulty in lignin chemistry is that no method has been established by which it is possible to isolate lignin in its native state from the fibre [45].

- Suberin is a natural biopolymer typically found in the cell walls of plants [46]. The structure of suberin in cork (i.e. its main chemical component) is not yet fully understood. It 
has been proposed that suberin consists of a polyester structure composed of long chain fatty acids, hydroxy fatty and phenolic acids, linked by ester groups $[4,47,48]$.

The chemical composition of fibres, in terms of cellulose, lignin and hemicelluloses contents, was found to have a strong influence on the mechanical properties of composites [49]. The most efficient natural fibres have been considered those that have high cellulose content coupled with a low microfibrile angle, resulting in high mechanical properties of the fibre $[26,30]$. Some studies using natural fibres showed that the lignin content on the surface of the fibres appeared to influence the degree of interfacial bonding: fibres with low lignin surface content gave better mechanical results than fibres with high lignin on the surface $[50,51]$ but with lower water resistance. In a study of wood plastic composites, the removal of hemicellulose from the fibres reduced water absorption and thickness swelling of the composites [51]. The mechanical properties of glass fibres are considerable superior as compared with the natural fibres as presented in Table 5.1 Wambua et al. [52] have compared the capability of some natural fibres to reinforce polyolefins and compared with the properties of glass reinforced ones. The study revealed that the composites containing kenaf, sisal and hemp fibres showed comparable tensile strength and modulus results. All these examples show the importance and complexity of the chemical composition of the lignocellulosic fibres and demonstrate their potential to reinforce polyethylene.

The advantages in the use of lignocellulosic fibres are not only related to the mechanical performance to reinforce polyethylene. Coir as natural reinforcing in polymeric matrices presents inferior performance due to several factors such as low cellulose content, high lignin content, high microfibrillar angle and large variable diameter [7]. Although the fibre is considered a poor reinforcing because of its low strength and modulus, it has found high interest due to its low density, low thermal conductivity and high elongation [5]. Another example is cork, the bark of the cork oak tree, with lower mechanical properties under tensile load. However, it has unique properties such as lowest density as compared with the natural fibres. Cork presents closed cell structure, viscoelastic properties and good insulation properties. It is also chemically inert, fire resistance, coefficient of Poison near zero and resistance to microbial decay $[4,53,54]$. Table 5.2 shows the main commercial lignocellulosic fibres with potential in the production of polymeric composites. These numbers shows the principal available material from renewable sources for new applications by using thermoplastic with lignocellulosic materials. Moreover, the properties of 
Table 5.2 Commercially major lignocellulosic sources (Adapted from [28, 54]).

\begin{tabular}{|l|c|}
\hline $\begin{array}{l}\text { Lignocellulosic } \\
\text { Source }\end{array}$ & $\begin{array}{c}\text { World Annual } \\
\text { Production (10 } \mathbf{3}^{\text {ton })}\end{array}$ \\
\hline Bamboo & 30,000 \\
\hline Jute & 2300 \\
\hline Kenaf & 970 \\
\hline Flax & 830 \\
\hline Sisal & 378 \\
\hline Cork & 374 \\
\hline Hemp & 214 \\
\hline Coir & 100 \\
\hline Ramie & 100 \\
\hline Abaca & 70 \\
\hline
\end{tabular}

natural fibres differ among cited works, due to the employment of different fibres, containing different moisture conditions, as well as due to different testing methods employed to evaluate these properties.

The performance of natural fibre reinforced polymer composites depends on several factors, including fibre chemical composition, cell dimensions, microfibrillar angle, defects, structure, physical and mechanical properties, and the interaction of a fibre with the polymeric matrix [28]. The knowledge about the characteristics of the fibre is essential in order to expand the effective use of lignocellulosic materials for polyethylene composites and to improve their performance.

\subsection{Coupling Agents and Fibre Chemical Treatments}

Lignocellulosic composites using polyolefins (including polyethylene) have gained increasing interest over the past two decades, both in the scientific community and industry [55]. The main drawback with the use of natural based components such as natural fibres in polyolefin composites is their hydrophilicity due to the high surface hydroxyl groups concentration which leads to poor interface and moisture resistance in composite materials [7]. The fibre-matrix interaction can be improved either via the fibre, 
usually by modifying its surface, or via the matrix, usually by employing additives called coupling agents [55].

\subsubsection{Coupling Agents used in Compounding}

Since high density polyethylene (HDPE) is relatively inert it is difficult to achieve good interfacial adhesion in composites. Often maleic anhydride grafted polyethylene is added to HDPE to improve interfacial adhesion to the reinforcing fibres [56].

Coupling is a common method of chemical modification. A coupling agent contains chemical groups which react with the fibre surface and the polymer matrix [5]. In such case, the interfacial bonding between the two components results in enhanced mechanical properties. Maleated polyolefins are the most widely used coupling agents $[17,28,57]$. They contain two functional domains: one a polyolefin typically high density polyethylene or polypropylene, which is able to form entanglements with the polymer matrix, and the second group, maleic anhydride, which is able to interact strongly with the lignocellulosic material at extrusion temperatures, covalently, via hydrogen, or ionic bonds [17]. Before compounding, special care should be taken since the maleated polyolefins can slowly react with air moisture during storage, and form free acid. As a result, chemical reactivity of the coupling agents decreases. Hence, should be kept the maleated polyolefins dry, or heat them up before usage in order to regenerate the anhydride chemical structure [17]. In the composite formulation containing natural reinforcements or fillers, the maleated polyolefins are usually used at $1-5 \%$ by weight $[17,58-60]$. In wood plastic composites the maleated coupling agent is the most expensive component representing $4-20 \%$ of the total cost of the materials in the formulation, whereas the plastic represents $60-80 \%$ of the formulation [17]. Several other coupling agents were also successfully tested as coupling agents or by improving the mechanical properties of polyolefins. These coupling agents included maleic anhydride (MA) [61-63], functionalized polyolefins including maleic anhydride graft polyethylene (PE-g-MA) [11, 12, 62, 64-87], maleic anhydride graft polypropylene (PP-g-MA) [50, 66, 67, 69, 88-90], styrene-ethylene/butadiene-styrene copolymer (SEBS) [66] and styrene-butadiene-styrene (SBS) $[61,91]$, silane based [87, 92-102], acrylic acid grafted polyethylene [62, 67], ethylene acrylic acid copolymer [69], phthalic anhydride (PA) [46, 103], epolene[57, 88, 92, 104], glycidyl methacrylate-grafted polyethylene [80], maleated ethylene [93], polyisocyanate[104], oxidized polyethylene [68], pentaerythritoltetracrylate (PETA) [46, 99], dicumyl peroxide (DCP) [99, 105-107], carboxylated polyethylene (CAPE) [70] and titanium-derived mixture (TDM) [70]. More recently, chemical components isolated from 
lignocellulosic materials such as lignin [108-111] and suberin or modified suberin $[46,112]$, were also suggested to improve the properties of polyolefins and its composites.

The use of coupling agents promotes a significant increase on the mechanical properties and in several studies it was showed that reduces the moisture content. Several of these studies revealed significant improvements on the modulus of elasticity, stiffness, tensile and/or flexural strength and fibre dispersion.

\subsubsection{Chemical Pre-Treatments of Lignocellulosic Fibres}

Lignocellulosic fibres are highly polar owing to the presence of hydroxyl groups $[7,9]$. The hydroxyl groups are readily available for chemical bonding (hydrogen bonding) with compatible polymer matrices and physical interlocking (wetting) with the non-polar matrices such as polyethylene. However, the presence of pectin and waxy materials along with hydroxyl groups, does not allow their bonding and wetting with the polymer matrices and make them less attractive for reinforcement $[32,113]$.

In lignocellulosic fibres, several chemical pre-treatments performed before compounding have been investigated by a number of researchers showing potential to remove waxes, oils from the surface and make it rough, active readily available hydroxyl groups or the introduction of new reactive site/groups; and to stop water uptake $[1,2,114-119]$. These treatments aim to improve fibre-matrix adhesion have achieved several levels of success in improving fibre strength, reducing water absorption and enhancing fibre-matrix adhesion in natural lignocellulosic composites.

Natural fibre modification relies on chemical and physical techniques to improve the interfacial interactions between the polyethylene matrix and the natural phase. The principal chemical and physical routes explored in polyethylene lignocellulosic fibre composites can be summarized as follows:

- Alkali Treatment: Mercerization or alkali treatment with strong alkali bases was developed as a method for cotton fibre modification by John Mercerin 1850 [55]. It is a common method to produce high quality natural fibres, by removing the natural and artificial impurities from the fibre surface. The chemical treatment reduces the fibre diameter and thereby increases the aspect ratio [26]. Mercerization is usually performed applying aqueous solutions of sodium hydroxide $(\mathrm{NaOH})$, at reaction times of $30 \mathrm{~min}$ up to $3 \mathrm{hr}$. 
Different degrees of modification are obtained by varying the concentration of the alkaline solution, the temperature and the extension of the treatment. Theoretically, other alkali types can be used as well, but sodium atoms have been shown to provide the optimal diameter for cellulose swelling, meaning that the treatment with $\mathrm{NaOH}$ is the most efficient [120]. In any case, excessive alkali has to be removed by washing the modified fibres/fillers subsequently, followed by a drying step [55]. Some studies [50, 116], indicate that the lignin content on the surface of fibres appeared to influence the degree of interfacial bonding. They found that chemical treatments remove the impurity and lignin, increasing the cellulose content of the natural fibre. As a result of alkali treatment, the removal of the surface lignin and hemicelluloses also exposes more active hydroxyl groups from cellulose to react with matrix improving properties with higher tensile strength, toughness and impact strength [51].

- Silane treatment: silane crosslinking is one way to improve the mechanical and long-term properties of wood plastic composites [97].The bifunctional structures of silanes have attracted their use in natural fibre/polymer composites, since both glass fibres and natural fibres bear reactive hydroxyl groups. Extensive research has been accordingly carried out to screen the varied silane structures for NFPC production. In order to effectively couple the natural fibres and polymer matrices, the silane molecule should have bifunctional groups which may respectively react with the two phases thereby forming a bridge in between them. Some reviews can be found in the literature discussing the potential of silanes $[3,95,117,118]$. It is possible to find that the use of silane to coat wood fibres produces an increase of $31 \%$ in the tensile strength and $124 \%$ in the tensile modulus, when compared to unfilled linear low density polyethylene (LLDPE) [121]. Bengtsson et al. used silane to crosslinking composites of wood flour and polyethylene [96, 97]. In both studies, composites of vinyltrimethoxysilane grafted high density polyethylene and wood flour were produced by compounding in a twin-screw extruder. The results showed an increase of the tensile strength with the increase of the amount of wood flour, which is an indication of improved adhesion between the matrix and the wood flour. Moreover, 
the study reported a clear reduction on the water absorption after fibre chemical treatment [96].

- Stearic acid: ... is an esterification method. The acid is added to an ethyl alcohol solution, up to $10 \%$ of the total weight of the fibres to be treated. The obtained solution is added drop wise on the fibres, which are then dried in oven [10]. In a study compounding PE-sisal composites by extrusion followed by compression moulding, the sisal fibres were treated with stearic acid. It was found that the fibre treatment with stearic acid increased the interfacial shear strength by $23 \%$ with respect to untreated fibres [122]. A different study performed using several natural fibres industrial crops (i.e. cotton stalk, rice straw, bagasse, and banana plant waste) compared the use of stearic acid and maleated polyethylene to reinforce the polyethylene. Better compatibility and enhanced mechanical properties were obtained when using maleated polyethylene as compatibilizer [49]. In a review on the modification methods for vegetable fibres for natural fibre composites [9], it was referred that by using an coupling agent, like silanes or stearic acid, the mechanical properties are promoted, dependent on the polymeric matrix.

- Peroxide treatment: Natural fibres are immersed in a solution of dicumyl (or benzoyl) peroxide in acetone for about half an hour, then decanted and dried [123]. Recent studies have highlighted significant improvements in the mechanical properties. In a study of polyethylene hybrid composites, sisal and glass fibres were proposed to reinforce the matrix in terms of tensile strength and modulus. Among different chemical treatments, benzoyl peroxide treated fibres revealed to be more successful. This was attributed to the peroxideinitiated grafting of polyethylene on to the fibres [124].

- Heat treatment: this treatment involves heating of the fibres or processing the composites at temperatures close to those at which the existing components of natural fibres began to degrade. When cellulose is heated it suffers physical and chemical changes. The physical properties affected by the heat treatment included the enthalpy, weight, strength, colour and crystallinity. Some studies on polyethylenelignocellulosic composites reflect the use of this treatment [125]. Sapieha et al. [126] studied the effect of this treatment on untreated cellulose fibres combined with LDPE. It 
was reported that the strength of the composites increased with the processing temperature and reached a maximum at $225^{\circ} \mathrm{C}$. Moreover, the increase in strength was accompanied by discoloration of the polyethylene composite material. Chemically the appearance of new peaks on the infrared FTIR analysis, which were not characteristics from the fibre or the matrix were suggested to be formed due to the degradation of the cellulose and from the oxidation of the polyethylene. Recently Kaboorani et al. [127, 128] investigated the treatment of pre-heat wood at different temperatures $\left(175,190\right.$ and $\left.205^{\circ} \mathrm{C}\right)$ in order to improve the compatibility of wood fibres with HDPE. Using wood treated at $190^{\circ} \mathrm{C}$ resulted in composites with the highest stiffness and tensile strength. Moreover, the treatment at $190^{\circ} \mathrm{C}$ resulted in good flexural properties and excellent water resistance of the wood-polyethylene composites [128].

- Plasma Treatment: Plasma is a fully or partially ionized gas, containing electrons, ions, high-energy neutral molecules and radicals. Usually, it accompanies ultraviolet (UV) photo emission [129]. Plasma is thought to bring a physical modification on the surface through roughening of the fibre by the sputtering effect, producing an enlargement of contact area that increases the friction between the fibre and the polymer [130]. This recent method in natural fibres allows to modify significantly the fibre surface without change the bulk properties of the material. However, chemical and morphological modification can be very heterogeneous depending on the treatment conditions. Therefore, process control is a critical aspect and the final surface modifications strongly depend on it [123]. This method is also applied to impart reactive groups on the polymeric surface and to promote polymer adhesion [9, 129-131]. In polyethylene-lignocellulosic composites, Felix et al. [132], studied the modification of cellulose fibres with oxygen plasma and characterised the interface in the system cellulose with LLDPE. By using single fibre fragmentation tests they show that after $15 \mathrm{~s}$ of oxygen plasma treatment the interfacial shear strength (IFSS) was increase $200 \%$. Furthermore, it was seen that after plasma the surface roughness of the fibres was reduced and by X-ray photo electron spectroscopy (XPS) it was shown the existence of hydroperoxide groups that could initiate grafting on 
the matrix chains. Other study, on LDPE-wood fibres composites, shows that in cold high frequency methane plasma improves the compatibility between fibre and the matrix. The tensile properties of polyethylene composites were improved and it was observed an increase in the hydrophobicity of the fibre [133].

\subsection{Composites Processing and Properties}

According to the standard ASTM D 3878, composite material is defined as a substance consisting of two or more materials, insoluble in one another, which are combined to form a useful engineering material possessing certain properties not possessed by the individual constituents [134]. Composites using natural component such as the use of natural fibres to reinforce the polymeric matrix are manufactured using traditional manufacturing techniques that includes compounding, mixing, extrusion, injection moulding, pultrusion, compression moulding, and rotational moulding systems $[28,153]$. Table 5.3 shows the studies developed on different polyethylene-lignocellulosic composite materials using these manufacturing processes. In this chapter, special emphasis is given to the extrusion because it is a process widely used to compound polyethylene with lignocellulosic materials and disperse additives such as foaming agents $[151,154]$, nanoclays and nanocellulose to reinforce [152, 155-157], colour and coating adhesion [131, 158, 159], organic [75, 111] and inorganic fire retardants $[160,161]$, antioxidant, thermal and ultraviolet (UV) stabilizers [111, 156, 162-164], fungal and decay resistance $[81,165-168]$, lubricant agents $[46,169,170]$. The aim is to improve the polyethylene-lignocellulosic composites properties. Problems concerning the processing of thermoplastics reinforced with lignocellulosic fibres are discussed in the literature $[3,28,171]$. One of the major issues in the development of composites containing polyethylene and lignocellulosic fibres is the thermal stability of the natural fibres. The production of natural fibre composites is strongly limited by the temperature and processing times begin seeing significant thermal degradation around $180-210^{\circ} \mathrm{C}$, or over $175^{\circ} \mathrm{C}$ for long periods with a significant decrease on the mechanical properties $[5,172]$. Therefore, the processing of these composites must be limited to temperatures at the lower range of this degradation range and for limited processing times avoiding significant fibre damage and reduced composite performance $[5,173]$. Barone et al. found that a natural fibre named keratin feather fibre is thermally stable for long periods 
Table 5.3 Reported work on polyethylene/lignocellulosic composites and manufacturing process.

\begin{tabular}{|l|l|l|l|}
\hline Natural Fibre & $\begin{array}{l}\text { Matrix } \\
\text { Polymer }\end{array}$ & Manufacturing Process & Ref. \\
\hline \multicolumn{4}{|c|}{ Polyethylene-natural fibre composites } \\
\hline Wood & HDPE & Extrusion & {$[69,135]$} \\
\hline Wood & HDPE & $\begin{array}{l}\text { Extrusion \& Injection } \\
\text { Moulding }\end{array}$ & $\begin{array}{c}{[66,74,} \\
81,136 \\
137]\end{array}$ \\
\hline Wood & HDPE & $\begin{array}{l}\text { Extrusion \& Compression } \\
\text { Moulding }\end{array}$ & {$[62,96]$} \\
\hline Bamboo & HDPE & $\begin{array}{l}\text { Extrusion \& Injection } \\
\text { Moulding }\end{array}$ & {$[138]$} \\
\hline Jute & HDPE & Extrusion & {$[139]$} \\
\hline Sisal & HDPE & Extrusion & {$[139]$} \\
\hline Cork & HDPE & Pultrusion\& Compression & {$[12,75]$} \\
\hline Agave & LMDPE & Rotational Moulding & {$[140]$} \\
\hline Sisal & HDPE & Rotational Moulding & {$[141,142]$} \\
\hline Wheat straw & HDPE & Blending \& Extrusion & {$[143]$} \\
\hline Sisal & LDPE & Extrusion & {$[114]$} \\
\hline Coir & LDPE & $\begin{array}{l}\text { Extrusion \& Compression } \\
\text { Moulding }\end{array}$ & \\
\hline Cork & LDPE & $\begin{array}{l}\text { Extrusion \& Compression } \\
\text { Moulding }\end{array}$ & {$[112]$} \\
\hline Pineapple Leaf & LDPE & Compression Moulding & {$[144]$} \\
\hline Wood & Recycled PE & Co-extrusion & {$[145]$} \\
\hline Wood & Recycled PE & Compression Moulding & {$[24]$} \\
\hline Peach Palm & Recycled PE & Compression Moulding & {$[146]$} \\
\hline Piassava & Recycled PE & Extrusion & {$[22]$} \\
\hline & & & $(C 07 t d i n g$ \\
\hline
\end{tabular}


Table 5.3 Cont.

\begin{tabular}{|c|c|c|c|}
\hline Natural Fibre & $\begin{array}{l}\text { Matrix } \\
\text { Polymer }\end{array}$ & Manufacturing Process & Ref. \\
\hline \multicolumn{4}{|c|}{ Hybrid polyethylene-natural fibre composites } \\
\hline Pine/Agave & HDPE & $\begin{array}{l}\text { Extrusion \& Injection } \\
\quad \text { Moulding }\end{array}$ & {$[147]$} \\
\hline Cork / Coir & HDPE & $\begin{array}{l}\text { Extrusion \& Compression } \\
\quad \text { Moulding }\end{array}$ & $\begin{array}{c}{[76,82} \\
148]\end{array}$ \\
\hline Cork / Sisal & HDPE & $\begin{array}{l}\text { Extrusion \& Compression } \\
\quad \text { Moulding }\end{array}$ & {$[82,149]$} \\
\hline Cork / Wood & HDPE & $\begin{array}{l}\text { Extrusion \& Compression } \\
\text { Moulding }\end{array}$ & {$[82]$} \\
\hline Sisal / Glass & LDPE & $\begin{array}{l}\text { Solution mixing \& } \\
\text { Compression Moulding }\end{array}$ & [124] \\
\hline Cotton/Flax & Recycled PE & Compression Moulding & {$[23]$} \\
\hline Kenaf & $\begin{array}{c}\text { Recycled } \\
\text { HDPE/ } \\
\text { Rubber }\end{array}$ & $\begin{array}{l}\text { Mixing \& Compression } \\
\text { Moulding }\end{array}$ & {$[20]$} \\
\hline \multicolumn{4}{|c|}{ Polyethylene composite blends and micro-nano reinforced } \\
\hline Lignin & LDPE & $\begin{array}{l}\text { Mixing \& Compression } \\
\text { Moulding }\end{array}$ & {$[109]$} \\
\hline $\begin{array}{l}\text { Lignin or } \\
\text { Suberin }\end{array}$ & HDPE-Cork & $\begin{array}{l}\text { Extrusion \& Compression } \\
\text { Moulding }\end{array}$ & {$[150]$} \\
\hline Cellulose & HDPE & Extrusion & {$[151]$} \\
\hline Cellulose & LDPE & $\begin{array}{l}\text { Mixing \& Compression } \\
\text { Moulding }\end{array}$ & {$[98]$} \\
\hline Cellulose & LDPE & Two-roll mill & {$[64]$} \\
\hline $\begin{array}{l}\text { Cellulose } \\
\text { whiskers }\end{array}$ & LDPE & Extrusion & {$[152]$} \\
\hline
\end{tabular}


of time up to $200^{\circ} \mathrm{C}$, although the best composite properties were found at processing temperatures of $205^{\circ} \mathrm{C}$, where the fibres are only stable for a few minutes. This clearly shows that thermoplastics such as polyethylene are the right option to be used as matrix when combined with lignocellulosic materials.

The moisture content at a given relative humidity, can have also a great effect on the biological performance of a composite made from natural fibres [28]. For example, the low moisture of cork can be regarded as one of the advantages of cork to be selected as natural component in composites design, since it is a hydrophobic material. In this section, special attention is given to the extrusion process because, it is the main processing route to compound both components (i.e. polyethylene and lignocellulosic material) and, on the other hand, it allows to obtain different varieties of polyethylene composite as either the final product or in the pellet form to be applied in a subsequent process such as compression or injection moulding. Overall, the selection of the processing route should take into account the desired final product.

\subsubsection{Extrusion}

Processing natural fibres in plastic with an extruder presents unique challenges, but these challenges can be overcome by the application of engineering principles [174]. The extrusion process is used by the plastic industry for the production of granules and also in the continuous production of semi-finished products or components. Single screw as well as twin-screw extruders that run either co- or counter-rotating may be used for this process. Single screw extruders are used when the mixing effect does not have to be very high. However, using a single screw configuration it was found that at higher processing temperatures it is possible to induce more alignment of natural fibres in the flow direction [139].

The excellent mixing effect of twin-screw extruder is that the natural fibre materials can be homogeneously distributed and wetted in the polymer melt [28, 171]. For instance, counter-rotating twin-screw extruders are mainly used in the processing of wood fibre reinforced thermoplastics; as the screws run in opposite directions, a secure material feed and a defined compacting of the material can be achieved [171]. The main advantages and disadvantages of both systems to process natural fibre composite systems are compared in Table 5.4. It should be noted that in order to produce the the polyolefin lignocellulosic composite pellets, and after the extrusion process, these factors must be taken into account. 
Table 5.4 Counter-rotating versus co-rotating extruders (Adopted from [174]).

\begin{tabular}{|c|c|c|}
\hline & Counter-Rotating & Co-Rotating \\
\hline Advantages & $\begin{array}{l}\text { Low screw speed suitable } \\
\text { for very shear-sensitive } \\
\text { products; } \\
\text { Positive pump - develops } \\
\text { high pressures. }\end{array}$ & $\begin{array}{l}\text { Higher power - higher } \\
\text { throughput potential; } \\
\text { Flexible screw design; } \\
\text { Excellent dispersive and } \\
\text { distributive mixing. }\end{array}$ \\
\hline Disadvantages & $\begin{array}{l}\text { Lower power - less } \\
\text { throughput potential; } \\
\text { Screw design option limited; } \\
\text { Limited dispersive mixing: } \\
\text { poor distributive mixing. }\end{array}$ & $\begin{array}{l}\text { Less positive pump - may } \\
\text { require gear/screw } \\
\text { pump to generate high } \\
\text { pressure; } \\
\text { Higher screw speed } \\
\text { not suitable for very } \\
\text { shear-sensitive products. }\end{array}$ \\
\hline
\end{tabular}

The results show that the lignocellulosic content and the type of plastic used are the main parameters that control the physical properties of composites. Some of the thermoplastic materials exhibit mechanical properties comparable to those of customary wood fibre products, i.e., medium density fibreboard (MDF) [99, 175]; however they show distinctly better behaviour than the MDF and natural wood after exposure to moisture [75, 99, 175].

In polyolefin with lignocellulosic fibres, co-extrusion technology has been pointed out as advanced polymer processing technology due to the unique capacity in creating a multi-layer composite with different complementary layer characteristics, and in making the properties of the final products highly "tunable" $[145,176,177]$. Generally, co-extrusion consists of two or more extruders combined with one die to produce multiple-layer products. In this process two or more polymer materials are extruded and converged upon a single die to form a unique multilayer structure [145, 178]. Properties, such as water resistance, air entrapment, oxygen barrier, and increased toughness are some of the advantages of coextruded products [178]. Based on a co-extruded core-shell structure of wood polymer composites (WPC) system, Huang et al. [176], investigated the shell layer, made of thermoplastics such as LDPE and HDPE unfilled/filled with minerals or natural fibres and other additives. It was shown that these organic/inorganic materials play an important role in enhancing the overall properties of the composite material. The core-shell structure profiles 
can significantly improve flexural and impact strengths of polyethylenelignocellulosic composites. Stark and Matuana [179] evaluated the moisture uptake, flexural properties and weathering performance between non-coextruded and coextruded wood plastic composites (WPC) with HDPE or a polypropylene (PP) shell. In their research, co-extruded WPC demonstrated reduced moisture uptake than non-coextruded WPC and there were no significant differences in the flexural properties.

Extruders are an ideal reactor, which serves as a pressure vessel, for polymer modification. It enables intensive mixing, shear, control of temperature and residence time, venting of by-product and transport of molten polymer through the various sections of the extruder, each serving as a mini-reactor. It is economically attractive because the extrusion and the processing are done in a single stage without chemical solvents emissions [180]. Studies based on polyethylene wood composites [181, 182] focused on the potential to graft maleic anhydride by a reactive extrusion process to improve fibre-matrix interface. Luo et al. [181] investigated the potential to graft maleic anhydride the wood fibre on HDPE by reactive extrusion. The results showed an increase of $112 \%$ and $36 \%$ in tensile and impact strength properties respectively; however, a slight decrease in thermo-stability of the polyethylene composites was also reported.

The extruder was also used to compound HDPE and wood with chemical foaming agents. The propose was to obtain composites with lower density [154]. The results of this study indicated that the use of coupling agent in the formulation was required to achieve HDPE/wood composite foams with high void fraction.

The use of the main chemical components of lignocellulosic fibres e.g. cellulose, lignin and/or suberin have been found to enhance the properties of polyethylene and its composites. Cellulose microcrystals (so-called "whiskers") obtained from different cellulose sources such as wood, were also applied as reinforcing agent. One of the few studies reports that these microcrystals were used in grafting of the cellulose nanowhiskers during extrusion. Long chain fatty acids have been used to successfully extrude cellulose nanowhiskers with LDPE. The homogeneity of the ensuing nanocomposites was found to increase with the length of the grafted chains resulting in a significant improvement in terms of elongation at break [152]. These nanostructures are used to produce nanocomposites and reinforce the properties of the materials. Palaniyandi and Simonsen [183] studied microcrystalline cellulose as filler compounded with HDPE in the presence of coupling agent to disperse cellulose. The presence of microcrystalline cellulose (i.e. polar substance) does not improve the 
thermoplastic properties. The study revealed that microcrystalline cellulose and/or compatibilizer increased the matrix degree of crystallinity without affect the stiffness of the developed composite. Moreover the compatibilizer improved the strength of the composites.

The production of new polyolefin blends or composites containing lignins could lead to a reduction in the use of petrol, a non-renewable resource of polyolefins. Thus, lignin valorisation could also improve the carbon footprint of the polyolefin production contributing to create new value added products. Doherty et al. [184], reports in different studies polyolefins were already combined with lignins derived from different sources. These polyolefin matrixes included preferably polypropylene $[110,185]$ and polyethylene as matrix $[109,150,163,186,187]$. Levon et al. [187] have successfully proposed the improvement of the thermal stabilization of polyethylene with lignin derivates. The rheological results of the polymer melt indicated that a reaction occurred during processing. Pucciariello et al. [163] have studied blends of lignin powder with different polyethylene grades. The obtained blends revealed slightly increases in the modulus for most lignin-polymer blends, whereas the tensile stress and elongation reduced. Moreover, lignin acted as a stabilizer against the UV radiation forLDPE and LLDPE grades. Indeed, these new products have the potential to improve the economy in the pulp and paper industry, which in the context of biorefinery would also contribute to the decrease of greenhouse gases by using, even if partially, more natural product instead of synthetic ones [184].

Fernandes et al. [112, 150], successfully proposed the use of the main chemical component of cork (i.e. isolated suberin and lignin) as biobased coupling agents through a reactive extrusion process to improve HDPE-cork interfacial bonding. Benzoyl peroxide (BPO) was used as the initiator. The outcomes of this research confirmed that composites with coupling agent present higher mechanical properties, lower water uptake and reduced thickness swelling variation. Suberin acted as plasticizer agent with antioxidant benefits for the polyethylene composites, while lignin works as a coupling agent, increasing both tensile modulus and strength and improved the thermal stability [150]. In another work, the same methodology using LDPE was applied and a modified suberin from cork and birch outer bark [112]. The morphology of the LDPE-cork composites showed good adhesion and the mechanical results confirmed that the addition of suberin acted as a coupling agent, improving the strength and leading to cork-polyethylene composite materials with improved strain. 


\subsubsection{Compression Moulding}

The compression moulding is a common processing technique in the manufacture of natural fibre composites due to of its high reproducibility, simplicity and versatility $[5,28,171]$. Compression moulded materials combined with natural fibres are used in the automobile industry to produce car interior lining parts. The main reason for this application is the great strength and stiffness and the low composite density of the natural fibre composites [171]. Compression moulding and extrusion are the standard processes to combine products of polyolefin with natural fibres. Table 5.3 indicates several studies where compression moulding was used as a second melting process to give the final shape to polyethylenelignocellulosic composite products $[23,62,75,96,98,109,124,188]$. A big concern with compression moulding that needs always to be considered is the maximum pressure before the damage of the fibres and the composite structure [43]. Compression moulding was also applied in a single step process to obtain the final product. Wolcott [189], addressed the use of flat-pressed wood-polyethylene composites. By using this hot-pressing technique, it was found that both the amount of HDPE and the melt flow index (MFI) of the selected polyolefin significantly influenced the flexural behaviour of the pressed panels. Thus, the panel stiffness was improved with decreased levels of HDPE and low MFI values. The use of wax and zinc stearate in the formulation decreased panel stiffness and enhanced the moisture resistance.

\subsubsection{Injection Moulding}

The injection moulding process allows manufacturing, within short periods of time, complex geometric components with functional elements, fast and also in high volumes [171]. Injection moulding is a major plastic forming process in which the components used to obtain the final material goes through five stages: (1) mould closing, (2) filling, (3) packing-holding, (4) cooling and (5) mould opening are preceded repeatedly. The injection moulding is widely used in the industry for plastic processing because, as a cyclic process, leads to high production rates on complex shape products with good dimensional accuracy and surface finishing [190]. It is a high-pressure process with machine capital costs and tooling costs generally high, if compared to other composites processing routes. Nevertheless, these costs can be recovered through inherent short cycle times, automation, and low labour costs [191]. The 
processing parameters during injection moulding are expected to have a strong influence on polyethylene composite properties. Indeed, two aspects that influence the end-product must be considered (i) the injection moulding process causes orientation of the polyethylene molecules within the sample due to the shear introduced during injection and (ii) the rapid cooling of parts within the mould produces parts with skin and core layers, caused by the different crystallization rates of the polymer within the part. Consequently, different properties on the moulded part can be obtained.

The injection moulding process has been used in several cases [51, 137, 159, 192-197] aiming to obtain the final composite product mainly after the extrusion, because it allows to get the final shape of the specimens. This melt-based process it may also contribute to the natural fibre length reduction. Bouafif et al. [196] showed that the major reduction in wood particle length was found to occur in the compounding process. In this study, extrusion and injection moulding contributes to particle length reduction. Conversely, compression moulding did not cause significant damage to wood particles. This particle reduction and the correct dispersion of the natural fibres in the matrix can benefit the mechanical properties of polyethylene-lignocellulosic composites.

The evolution of the technology lead to a combination of injection moulding and extrusion into a single machine, was developed by KraussMaffei, a Germany company. In this step also called as injection moulding compound (IMC) process, the polyolefin and the lignocellulosic fraction are compounded. This method offers advantages in terms of reduced production costs and the material is heated just once in this one step process [198]. This is a way to protect the natural fibres from degradation avoiding the two thermal cycles, i.e. the extrusion to obtain the composite pellets and the injection moulding to obtain the product.

\subsubsection{Pultrusion}

Pultrusion is an automated process to produce continuous and constant-cross-section composites [5]. Long-fibre reinforced thermoplastic materials or composite granules are usually produced with the pultrusion process. At the exit of this system the cross-section of the strand is calibrated by a nozzle, then cooled and granulated [171]. In this process the material mixture is equally plastified with frictional heat and pressure. Resulting steam is vacuumed off. The pultruded material is pneumatically transported into a granulator which produces a homogeneous and uniform granule [199]. Advantages of this process are the ability to build thin 
wall structures, the large variety of cross-sectional shapes and the possibility for high degree of automation [43].

Based on a R\&D collaboration between the industry and academia, polyolefins to compound with cork sub-products was selected [12, 75]. HDPE was combined with different cork sub-products derived from industrial processes, with the same weight proportion, by using this melt based technology followed by compression moulding. The composite pellets showed lower density as compared with the used matrix and the cork particles were well dispersed. The tensile strength of the composites was improved by the use of a coupling agent based on maleic anhydride [12]. Comparing the properties of the developed composites with well-established medium and high density fibreboard (MDF) and (HDF) materials it was found that the polyethylene-cork composites showed good dimensional stability, lower water uptake, a better acoustic insulation performance and similar behaviour in terms of hardness and fire resistance when compared with both MDF and HDF. These polyethylene composites showed important characteristics to be considered as good candidates to be applied in the design of flooring and construction systems. [75].

\subsubsection{Rotational Moulding}

Rotational moulding or rotomolding is a process used mainly for the manufacture of hollow plastic parts with low internal stresses at an economic cost, if compared to other manufacturing processes. Some of the typical products manufactured with rotational moulding are toys, balls and storage tanks. More recently, the rotational moulding of HDPE has gained considerable importance, due to unique advantages in the manufacture of hollow plastic products $[141,200]$. Polyethylene is the main material used in this technology; indeed, about of $85 \%$ of the rotomoulded parts produced worldwide are made from PE [201]. This is mainly due to low melting point, low cost, and good thermal stability of this material; on the other hand, $\mathrm{PE}$ has lower mechanical properties than other polymers, which is a limitative factor in high performance applications [2]. One of the most common defects in rotomoulded parts is the appearance of bubbles [202]. In order to understand the potential of combining natural fibres to reinforce polyethylene by rotational moulding Torres and Aguirre [203] used jute, sisal and cabuya, as well as wood, pecan and rice shell flour of different types. The study reports improvements in the compression strength of the natural fibre reinforced rotomoulded products, when compared to the unreinforced materials. In addition, a good dispersion level of the natural fraction in the fibre or powder form is observed. 


\subsection{Industrial Applications of Polyethylene with Lignocellulosic Fibres}

Polyethylene is the largest volume plastic produced in the world and is rather soft, making PE-based composite easier to nail, screw, cut, and saw [17]. The combination of thermoplastic materials, as polyethylene, with the unique properties of the lignocellulosic materials opens the prospective of new uses and applications. Well-known trade names are presented in Table 5, showing several of the commercial products developed by using polyethylene with lignocellulosic fibres. The composite products are mainly focused on the use of polyethylene (i.e. HDPE and LDPE) and recycled polyethylene as the matrix. Moreover, it was observed for these products a minimum of lignocellulosic component of $35 \mathrm{wt}$.\% up to $70 \mathrm{wt} . \%$. Potential applications of these composite materials are mainly towards the consumer and industrial use; automotive sector; and in construction in load floors. Indeed, polyethylene-lignocellulosic materials are found in outdoor deck floors, railings, fences, landscaping timbers, cladding and siding, park benches and indoor furniture.

In the case of automotive applications, polypropylene seems to be the preferable choice as matrix. In this context, in 1940 Henry Ford envisaged a car door made by hemp fibres and polyethylene. Several patent and patent applications can be found in the literature revealing the potential of the polyethylene with natural fibres for different areas of application $[82,158$, 170, 208-213].

There is a variety of composites products in the market using polyethylene matrix with lignocellulosic fibres. As pointed before, these commercial products could originate from recycled or virgin polyethylene grades. Most of them are decking products as shown in Figure 5.2 that contain wood fibres, dust or flour. Composites based on wood and high density polyethylene, both recycled and virgin, are mostly used in exterior building components [214].

There are a diversity of formulas to produce the composite material, some of them using recycled materials in terms of matrix and natural reinforcement, although the trend seems to be less recycled material and more virgin polyethylene for higher quality boards. Chemical additives such as anti-UV agents, Anti-oxidation agents, stabilizers, colorants, anti-fungi agents, coupling agents, reinforcing agents, and lubricants, among others, are added to the formulation to improve the composite performance. The physical and chemical treatments including the use of coupling agents on polyethylene-lignocellulosic composites showed to improve fibre-matrix 
Table 5.5 Listing of some commercial products available in the market (Compiled from [204-207]).

\begin{tabular}{|c|c|c|c|}
\hline Name & Plastic Type & Fibre (wt.\%) & Application \\
\hline Premier & HDPE & Wood flour & Decking \\
\hline Durawood & HDPE & Wood & $\begin{array}{l}\text { Decking, benches, } \\
\text { picnic tables }\end{array}$ \\
\hline Latitudes & HDPE & $>50 \%$ wood flour & Decking \\
\hline Mikron & $\begin{array}{l}\text { HDPE, } \\
\text { LDPE }\end{array}$ & $\begin{array}{l}\text { Hardwood and } \\
\text { softwood flour }\end{array}$ & Decking \\
\hline Timbertech & HDPE & $50 \%$ wood flour & $\begin{array}{l}\text { Deking, solid and } \\
\text { slotted boards }\end{array}$ \\
\hline Fiberon & $\begin{array}{l}\text { HDPE, } \\
\text { LDPE }\end{array}$ & $\begin{array}{l}50 \% \text { wood flour, oak } \\
\text { and pine }\end{array}$ & $\begin{array}{l}\text { Deking, slotted } \\
\text { boards }\end{array}$ \\
\hline NCell & $\mathrm{PE}$ & $\begin{array}{l}40 \% \text { natural cellulosic } \\
\text { microfibres }\end{array}$ & $\begin{array}{l}\text { Consumer \& } \\
\text { Industrial; } \\
\text { automotive; load } \\
\text { floors }\end{array}$ \\
\hline Weatherbest & HDPE & Recycled wood fibres & Slotted boards \\
\hline $\begin{array}{l}\text { JERtech } \\
\text { Envirotech }\end{array}$ & $\mathrm{PE}$ & $\begin{array}{l}\text { Pine, oak, maple and } \\
\text { rice hulls }\end{array}$ & $\begin{array}{l}\text { Consumer goods, } \\
\text { toys, and } \\
\text { construction. }\end{array}$ \\
\hline JadeMask & $\begin{array}{l}\mathrm{HDPE} \\
\text { recycled }\end{array}$ & $70 \%$ recycled bamboo & $\begin{array}{l}\text { Decking \& railing } \\
\text { systems, garden } \\
\text { box }\end{array}$ \\
\hline EverGrain & $\begin{array}{l}\text { HDPE } \\
\text { recycled }\end{array}$ & Wood fibres dust & Decking \\
\hline $\begin{array}{l}\text { Carefree } \\
\text { Composite }\end{array}$ & $\begin{array}{l}\text { HDPE } \\
\quad \text { recycled }\end{array}$ & $\begin{array}{l}35 \% \text { wood and natu- } \\
\text { ral fibres }\end{array}$ & Decking \\
\hline Nexwood & $\begin{array}{l}\text { HDPE } \\
\quad \text { recycled }\end{array}$ & $60 \%$ rice hull flour & Decking \\
\hline BamDeck & $\begin{array}{l}\mathrm{HDPE} \\
\text { recycled }\end{array}$ & $60 \%$ Bamboo & Decking \\
\hline
\end{tabular}


Table 5.5 (Cont.)

\begin{tabular}{|l|l|l|l|}
\hline Name & Plastic Type & Fibre (wt.\%) & Application \\
\hline Duradeck & $\begin{array}{c}\text { HDPE } \\
\text { recycled }\end{array}$ & Oak fibre & Decking \\
\hline EverGrain & $\begin{array}{c}\text { HDPE } \\
\text { recycled }\end{array}$ & Wood fibres dust & Decking \\
\hline Trex & PE recycled & $50 \%$ hardwood fibres & Decking \\
\hline Choicedek & $\begin{array}{c}\text { HDPE } \\
\text { recycled }\end{array}$ & Red oak fibres & $\begin{array}{c}\text { Decking, solid and } \\
\text { Slotted boards }\end{array}$ \\
\hline
\end{tabular}

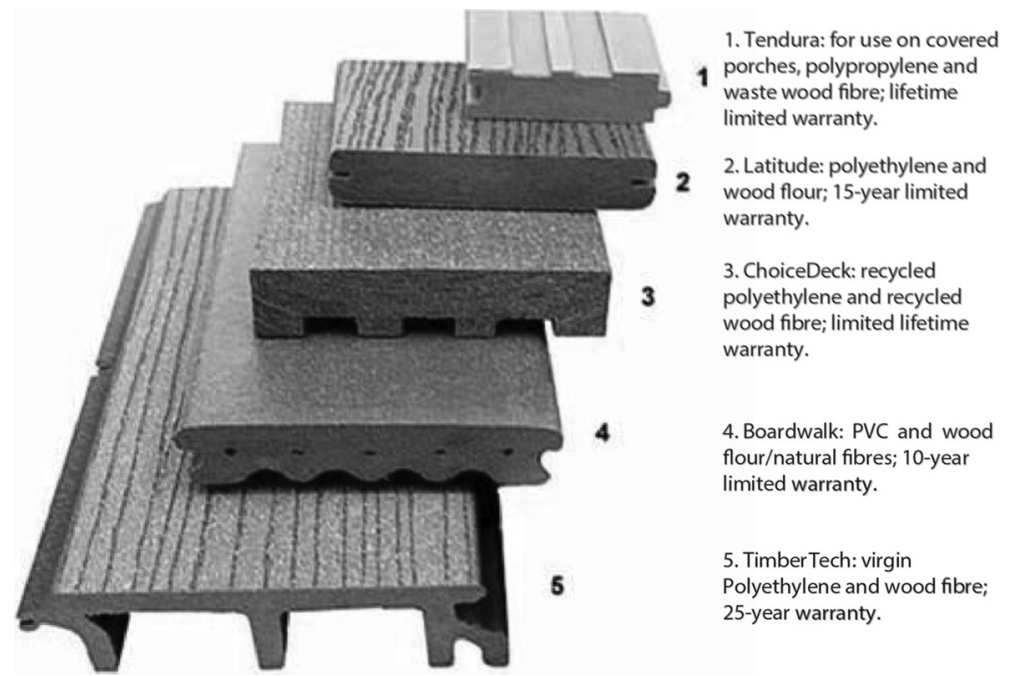

Figure 5.2 Thermoplastics with natural fibre market products for decking applications [215].

adhesion. With this, the fibre strength has been promoted and consequently led to higher mechanical resistance of the composites. Moreover, it is seen that the moisture content is reduced whereas the outdoor performance is increased [118]. The evolution and perfection of some of the polyethylene composite products (e.g. EverGrain and Trex) simulates/copy natural wood species, presenting embossed grain via compression moulding process. 


\subsection{Conclusions and Future Trends}

The uses of lingocellulosic material from renewable sources as reinforcing agent in terms of mechanical, insulation and/or aesthetic properties in polyethylene composites is reviewed. Based on information found in literature, and herein presented, the properties of natural fibre-reinforced composites are shown to be, in the most cases, superior to those of the unreinforced ones, when dealing with polyethylene and lignocellulosic fibres. The fire proofing characteristics of the natural fibre polyolefin composites will take special attention. Indeed, the flammability performance of composite applications e.g. building and transportation must follow the safety regulations independently of the high structural performance of these materials. The selection of flame retardants should provide the maximum effectiveness and the minimum secondary effects in a fire satisfying, at the same time, all environmental and toxicological requirements. The type of natural fibre will promote the fire resistance; however for higher amounts of fibre used as reinforcing it is expect some limitations on the amount of flame retardant due to processing conditions.

In the natural fibre polyolefin composites, the antimicrobial protection should not be neglected. Moreover, accelerated tests should be performed in order to achieve the optimal antimicrobial protection by using specific additives.

Colour and UV resistance of the natural fibre polyolefin composites will continue to be a key issue. The colour of some natural fibre composites fade in a short time. As aforementioned, the chemical composition of the natural fibres shows quite significant variations. In this context, new and efficient strategies are essential in order to guarantee that the developed polyethylene composites are able to sustain larger exposure periods to the light and weather conditions. At the moment, colouring the polymer matrix with organic pigments is one of the most effective ways to colour these composites. Another issue is the potential to recycle and reuse these polyethylene composites with lignocellulosic fibres. More effort to determine the resistance of these recycled composite systems and the maximum number of processing cycles without significant failure in terms of colour stability and mechanical performance should be conduct to the final products. In addition, tests under extreme environment conditions and the development of means to enhance that resistance will become critical to the use of the final products. In the context of eco-friendly products, polyethylene sub-products and natural fibre sub-products can be used as raw material for the production of alternative materials in architecture in urban or rural 
areas. Nevertheless, the market trend showed an increased interest in the use of virgin polyethylene to obtain competitive composite products with improved performance and lifetime. As far as the technology is concerned, the development of in-line monitoring systems to identify the changing of material characteristics during processing and moulding cycles will bring new knowledge and enhance the understanding about the effective behaviour of these composite materials. Further investigation on the application, development and commercialisation of suberin and specially lignin, cellulose and cellulose whiskers is needed. Mainly as components to improve the characteristics of the polyethylene composites, which will bring benefit to the final product in specific key areas.

\section{References}

1. A. K. Bledzki, and J. Gassan, Composites reinforced with cellulose based fibres. Prog. in Poly. Sci. 24 (2), 221-74 (1999).

2. D. N. Saheb, and J. P. Jog, Natural fiber polymer composites: A review. Adv. in Polym. Tech. 18 (4), 351-63 (1999).

3. A. K. Bledzki, S. Reihmane, and J. Gassan, Thermoplastics reinforced with wood fillers: A literature review. Polym.-Plast. Tech. and Eng. 37(4), 451-68 (1998).

4. S. P. Silva, M. A. Sabino, E. M. Fernandes, V. M. Correlo, L. F. Boesel, and R. L. Reis, Cork: properties, capabilities and applications. Int Mater Rev. 50 (6), 345-65 (2005).

5. M. A. Fuqua, S. S. Huo, and C. A. Ulven, Natural Fiber Reinforced Composites. Polym. Rev. 52 (3-4), 259-320 (2012).

6. D. D. Stokke, and D. J. Gardner, Fundamental aspects of wood as a component of thermoplastic composites. J. of Vinyl and Addit. Tech. 9 (2), 96-104 (2003).

7. A. Bismarck, A. K. Mohanty, I. Aranberri-Askargorta, S. Czapla, M. Misra, G. Hinrichsen, et al. Surface characterization of natural fibers; surface properties and the water up-take behavior of modified sisal and coir fibers. Green Chem. 3 (2), 100-7 (2001).

8. Y. Li, Y. -W. Mai, and L. Ye, Effects of fibre surface treatment on fracturemechanical properties of sisal-fibre composites. Composite Interfaces. 12 (1-2), 141-63 (2005).

9. A. K. Bledzki, S. Reihmane, and J. Gassan, Properties and modification methods for vegetable fibers for natural fiber composites. J. of App. Polym. Sci. 59 (8), 1329-36 (1996).

10. E. Zini, and M. Scandola, Green Composites: An Overview. Polym. Comp. 32 (12), 1905-15 (2011). 
11. J. Z. Lu, I. I. Negulescu, and Q. L. Wu, Maleated wood-fiber/high-densitypolyethylene composites: Coupling mechanisms and interfacial characterization. Comp. Interfaces 12 (1-2), 125-40 (2005).

12. E. M. Fernandes, V. M. Correlo, J. A. M. Chagas, J. F. Mano, and R. L. Reis, Cork based composites using polyolefin's as matrix: Morphology and mechanical performance. Comp. Sci. \& Tech. 70 (16), 2310-8 (2010).

13. M. Gahleitner, Melt rheology of polyolefins. Prog. in Polym. Sci. 26 (6), 895944 (2001).

14. V. Mittal, Polyolefin Nanocomposites Technology. In Advances in Polyolefin Nanocomposites. V. Mittal (Ed.), pp. 1-21, CRC Press Taylor \& Francis Group (2011).

15. L. A. Utracki, Introduction to Polymer Blends. In Polymer Blends Handbook: Kluer Academic Publishers. L. A. Utracki (Ed.). pp. 1-96 (2002).

16. T. C. Chung, Functionalization of Polyolefins. Academic Press (2002).

17. A. A. Klyosov, Wood-Plastic Composites. John Wiley \& Sons, Inc. (2007).

18. A. Ashori, Municipal solid waste as a source of lignocellulosic fiber and plastic for composite industries. Polym.-Plastics Tech. \& Eng. 47 (8), 741-4 (2008).

19. S. Kazemi Najafi, Use of recycled plastics in wood plastic composites - A review. Waste Management 33 (9), 1898-905 (2013).

20. X. V. Cao, H. Ismail, A. A. Rashid, T. Takeichi, and T. Vo-Huu, Effect of filler surface treatment on the properties of recycled high-density polyethylene/ (natural rubber)/(Kenaf powder) biocomposites. J. of Vinyl and Add. Tech. (2014).

21. N. Lu, R. H. Swan, Jr., and I. Ferguson, Composition, structure, and mechanical properties of hemp fiber reinforced composite with recycled high-density polyethylene matrix. J. of Comp. Mat. 46 (16), 1915-24 (2012).

22. A. Elzubair, and J. C. Miguez Suarez, Mechanical behavior of recycled polyethylene/piassava fiber composites. Mat. Sci. \& Eng. a-Struct. Mat. Prop. Microstructure and Processing. 557, 29-35 (2012).

23. J. Foulk, W. Chao, D. Akin, R. Dodd, and P. Layton, Analysis of Flax and Cotton Fiber Fabric Blends and Recycled Polyethylene Composites. J. of Polym. \& the Environ. 14 (1), 15-25 (2006).

24. D. P. Kamdem, H. H. Jiang, W. N. Cui, J. Freed, and L. M. Matuana, Properties of wood plastic composites made of recycled HDPE and wood flour from CCA-treated wood removed from service. Comp. Part A-App. Sci. \& Manufacturing. 35 (3), 347-55 (2004).

25. A. K. Mohanty, M. Misra, and G. Hinrichsen, Biofibres, biodegradable polymers and biocomposites: An overview. Macromol. Mater. Eng. 276-277 (1), $1-24(2000)$.

26. G. Bogoeva-Gaceva, M. Avella, M. Malinconico, A. Buzarovska, A. Grozdanov, G. Gentile, et al. Natural fiber eco-composites. Polymer Composites. 28 (1), 98-107 (2007). 
27. W. Hu, M. -T. Ton-That, F. Perrin-Sarazin, and J. Denault, An improved method for single fiber tensile test of natural fibers. Polym Eng Sci. 50 (4), 819-25 (2010).

28. O. Faruk, A. K. Bledzki, H. -P. Fink, and M. Sain, Biocomposites reinforced with natural fibers: 2000-2010. Prog. in Polym. Sci. 37 (11), 1552-96 (2012).

29. M. Jawaid, and H. P. S. Abdul Khalil, Cellulosic/synthetic fibre reinforced polymer hybrid composites: A review. Carbohyd. Polym. 86 (1), 1-18 (2011).

30. D. Liu, J. Song, D. P. Anderson, P. R. Chang, and Y. Hua, Bamboo fiber and its reinforced composites: structure and properties. Cellulose 19 (5), 1449-80 (2012).

31. B. Alexander, M. Supriya, and L. Thomas, Plant Fibers as Reinforcement for Green Composites. Natural Fibers, Biopolymers, and Biocomposites. CRC Press (2005).

32. K. Majeed, M. Jawaid, A. Hassan, A. Abu Bakar, H. P. S. Abdul Khalil, A. A. Salema, et al. Potential materials for food packaging from nanoclay/ natural fibres filled hybrid composites. Materials \& Design. 46 (0), 391-410 (2013).

33. G. Siqueira, and J. Bras, A. Dufresne, Cellulosic Bionanocomposites: A Review of Preparation, Properties and Applications. Polymers. 2 (4), 728-65 (2010).

34. L. Brinchi, F. Cotana, E. Fortunati, and J. M. Kenny, Production of nanocrystalline cellulose from lignocellulosic biomass: Technology and applications. Carbohyd. Polym. 94 (1), 154-69 (2013).

35. D. Klemm, F. Kramer, S. Moritz, T. Lindström, M. Ankerfors, D. Gray, et al. Nanocelluloses: A New Family of Nature-Based Materials. Angewandte Chemie International Edition. 50 (24), 5438-66 (2011).

36. M. M. de Souza Lima, R. Borsali, Rodlike Cellulose Microcrystals: Structure, Properties, and Applications. Macromolecular Rapid Communications. 25(7), 771-87 (2004).

37. D. Klemm, D. Schumann, F. Kramer, N. Hessler, D. Koth, B. Sultanova, Nanocellulose Materials - Different Cellulose, Different Functionality. Macromolecular Symposia. 280, 60-71 (2009).

38. R. J. Moon, A. Martini, J. Nairn, J. Simonsen, and J. Youngblood, Cellulose nanomaterials review: structure, properties and nanocomposites. Chem Society Rev. 40 (7), 3941-94 (2011).

39. N. Lavoine, I. Desloges, A. Dufresne, and J. Bras, Microfibrillated cellulose - Its barrier properties and applications in cellulosic materials: A review. Carbohyd Polym. 90 (2), 735-64 (2012).

40. E. M. Fernandes, R. A. Pires, J. F. Mano, and R. L. Reis, Bionanocomposites from lignocellulosic resources: Properties, applications and future trends for their use in the biomedical field. Prog. in Polym. Sci. 38 (10-11), 1415-41 (2013).

41. H. El-Saied, A. H. Basta, and R. H. Gobran, Research progress in friendly environmental technology for the production of cellulose products (bacterial 
cellulose and its application). Polym.-Plastics Tech. and Eng. 43 (3), 797-820 (2004).

42. S. J. Eichhorn, Cellulose nanowhiskers: promising materials for advanced applications. Soft Matter. 7 (2), 303-15 (2011).

43. S. Kalia, A. Dufresne, B. M. Cherian, B. S. Kaith, L. Avérous, J. Njuguna, et al. Cellulose-Based Bio- and Nanocomposites: A Review. Inter. J. of Polym. Sci. 2011, 1-35 (2011).

44. F. T. Wallenberger, and N. Weston, Natural Fibers, Plastics and Composites. Kluwer Academic Publishers, New York, NY (2004).

45. M. J. John, S. Thomas, Biofibres and biocomposites. Carbohyd Polym. 71 (3), 343-64 (2008).

46. S. Koskimies, J. Hulkko, P. Pitkaenen, N. Heiskanen, J. Yli-Kauhaluoma, $\mathrm{K}$. Waehaelae, et al. Method for the manufacture of oligo- and polyesters from a mixture of carboxylic acids obtained from suberin and/or cutin and the use thereof. Valtion Teknillinen Tutkimuskeskus (2007).

47. N. Cordeiro, M. N. Belgacem, A. J. D. Silvestre, C. Pascoal Neto, and A. Gandini, Cork suberin as a new source of chemicals: 1. Isolation and chemical characterization of its composition. Int. J. Biol. Macromol. 22 (2), 71-80 (1998).

48. H. Pereira, Química da cortiça IV. determinação da suberina em cortiça virgem e em cortiça de reprodução de Quercus suber L. Anais Instituto Superior Agronomia. 40, 17-25 (1981).

49. Y. Habibi, W. K. Ei-Zawawy, M. M. Ibrahim, and A. Dufresne, Processing and characterization of reinforced polyethylene composites made with lignocellulosic fibers from Egyptian agro-industrial residues. Comp. Sci. \& Tech. 68 (7-8); 1877-85 (2008).

50. N. A. Miller, C. D. Stirling, and V. S. M. Vantilburg, Effects of fiber treatment on fiber/matrix interfacial bonding in pinus-radiata fibre/thermoplastic composites. Polym. \& Polym. Comp. 3 (2), 117-27 (1995).

51. R. Ou, Y. Xie, M. P. Wolcott, S. Sui, and Q. Wang, Morphology, mechanical properties, and dimensional stability of wood particle/high density polyethylene composites: Effect of removal of wood cell wall composition. Mat. \& Design. 58 (0), 339-45 (2014).

52. P. Wambua, J. Ivens, and I. Verpoest, Natural fibres: can they replace glass in fibre reinforced plastics? Comp. Sci. and Tech. 63, 1259-64 (2003).

53. J. Mano, The viscoelastic properties of cork. J. of Mat. Sci. 37 (2), 257-63 (2002).

54. H. Pereira, Cork: biology, production and uses. Amsterdam: Elsevier (2007).

55. L. Sobczak, O. Brüggemann, and R. F. Putz, Polyolefin composites with natural fibers and wood-modification of the fiber/filler-matrix interaction. J. of App. Polym. Sci. 127 (1), 1-17 (2013).

56. J. D. Muzzy, 2.02 - Thermoplastics - Properties. In Comprehensive Composite Materials. A . Kelly, and C . Zweben (Eds.), pp. 57-76, Oxford, Pergamon (2000). 
57. T. J. Keener, R. K. Stuart, and T. K. Brown, Maleated coupling agents for natural fibre composites. Compos Part A-Appl S. 35 (3), 357-62 (2004).

58. J. R. Araújo, W. R. Waldman, and M. A. De Paoli, Thermal properties of high density polyethylene composites with natural fibres: Coupling agent effect. Polymer Degradation and Stability. 93 (10), 1770-5 (2008).

59. Y. Lei, Q. Wu, F. Yao, Y. Xu, Preparation and properties of recycled HDPE/ natural fiber composites. Compos Part A-Appl S. 38 (7), 1664-74 (2007).

60. K. B. Adhikary, S. Pang, and M. P. Staiger, Long-term moisture absorption and thickness swelling behaviour of recycled thermoplastics reinforced with Pinus radiata sawdust. Chem. Eng. J. 142 (2), 190-8 (2008).

61. K. Oksman, Improved interaction between wood and synthetic polymers in wood/polymer composites. Wood Science and Technology. 30 (3), 197-205 (1996).

62. Q. X. Li, L. M. Matuana, Effectiveness of maleated and acrylic. acid-functionalized polyolefin coupling agents for HDPE-wood-flour composites. Journal of Thermoplastic Composite Materials. 16 (6), 551-64 (2003).

63. H. Gao, Y. Xie, R. Ou, Q. Wang, Grafting effects of polypropylene/polyethylene blends with maleic anhydride on the properties of the resulting woodplastic composites. Comp. Part A-Applied Sci. \& Manufacturing. 43 (1), 150-7 (2012).

64. T. J. Kim, Y. M. Lee, and S. S. Im, The preparation and characteristics of lowdensity polyethylene composites containing cellulose treated with cellulase. Polym. Comp. 18 (3), 273-82 (1997).

65. A. Sarkar, S. A. Pillay, R. R. N. Sailaja, M. Chanda, Thermoplastic composites from cyanoethylated wood and high density polyethylene. J. of Polym. Mat. 18 (4), 399-407 (2001).

66. S. M. Lai, F. C. Yeh, Y. Wang, H. C. Chan, and H. F. Shen, Comparative study of maleated polyolefins as compatibilizers for polyethylene/wood flour composites. J. of Appl. Polym. Sci. 87 (3), 487-96 (2003).

67. Y. Wang, F. C. Yeh, S. M. Lai, H. C. Chan, and H. F. Shen, Effectiveness of functionalized polyolefins as compatibilizers for polyethylene/wood flour composites. Polym. Eng. and Sci. 43 (4), 933-45 (2003).

68. J. Z. Lu, Q. L. Wu, and I. I. Negulescu, Wood-fiber/high-density-polyethylene composites: Coupling agent performance. J. of Appl. Polym. Sci. 96 (1), 93-102 (2005).

69. M. J. A Chowdhury, and M. P. Wolcott, Compatibilizer selection to improve mechanical and moisture properties of extruded wood-HDPE composites. Forest Products J. 57 (9), 46-53 (2007).

70. Y. Lei, Q. Wu, F. Yao, and Y. Xu, Preparation and properties of recycled HDPE/natural fiber composites. Composites Part A-Applied Science and Manufacturing. 38 (7), 1664-74 (2007).

71. S. Mohanty, and S. K. Nayak, Rheological characterization of HDPE/sisal fiber composites. Polym. Eng. and Sci. 47 (10), 1634-42 (2007). 
72. S. Leduc, J. R. G. Urena, R. Gonzalez-Nunez, J. R. Quirarte, B. Riedl, and D. Rodrigue, LDPE/agave fibre composites: Effect of coupling agent and weld line on mechanical and morphological properties. Polymers \& Polymer Comp. 16 (2), 115-23 (2008).

73. F. Mengeloglu, and K. Karakus, Some Properties of Eucalyptus Wood Flour Filled Recycled High Density Polyethylene Polymer-Composites. Turkish Journal of Agriculture and Forestry. 32 (6), 537-46 (2008).

74. K. Sewda, S. N. Maiti, Mechanical Properties of Teak Wood Flour-Reinforced HDPE Composites. J. of Appl. Polym. Sci. 112 (3), 1826-34 (2009).

75. E. M. Fernandes, V. M. Correlo, J. A. M. Chagas, J. F. Mano, and R. L. Reis, Properties of new cork-polymer composites: Advantages and drawbacks as compared with commercially available fibreboard materials. Comp. Struct. 93 (12), 3120-9 (2011).

76. E. M. Fernandes, V. M. Correlo, Mano JF, and R. L. Reis, Natural Fibres as Reinforcement Strategy on Cork-Polymer Composites. In Advanced Materials Forum Vi, Pts 1 and 2. A. M. P. Pinto, and A. S. Pouzada (Eds.). pp. 373-8 (2013).

77. R. M. Taib, S. Ramarad, Z. A. M. Ishak, and H. D. Rozman, Effect of Acetylation and MAPE on the Properties of Steam-Exploded Acacia mangium Fiber-HDPE Composites. J. of Reinforced Plastics and Comp. 29 (3), 431-44 (2010).

78. Y. Hamzeh, A. Ashori, and B. Mirzaei, Effects of Waste Paper Sludge on the Physico-Mechanical Properties of High Density Polyethylene/Wood Flour Composites. J. of Polym and the Environ. 19 (1), 120-4 (2011).

79. G. Li, R. Qi, and M. Huang, Glass Fiber/Wood Flour Modified High Density Polyethylene Composites. J. of Appl. Polym. Sci. 123 (4), 2084-9 (2014).

80. P. K. Aggarwal, S. Chauhan, N. Raghu, S. Karmarkar, and G. M. Shashidhar, Mechanical properties of bio-fibers-reinforced high-density polyethylene composites: effect of coupling agents and bio-fillers. J. of Reinforced Plastics and Comp. 32 (22), 1722-32 (2013).

81. A. Ashori, H. M. Behzad, and A. Tarmian, Effects of chemical preservative treatments on durability of wood flour/HDPE composites. Comp. Part B-Eng. 47, 308-13 (2013).

82. E. M. Fernandes, V. M. C. D. Silva, J. A. M. D. Chagas, and R. L. G. D. Reis, Fiber-reinforced cork-based composite. WO2011014085-A2; Amorim Revestimentos SA (2011).

83. A. H. Hemmasi, Study on the Tensile and Impact Properties of Bagasse Flour/Recycled High-Density Polyethylene Composite. Asian J. of Chem. 25(13), 7645-6 (2013).

84. N. -L. M. Robertson, J. A. Nychka, K. Alemaskin, and J. D. Wolodko, Mechanical performance and moisture absorption of various natural fiber reinforced thermoplastic composites. J. of Appl. Polym. Sci. 130 (2), 969-80 (2013). 
85. M. Tazi, F. Erchiqui, F. Godard, H. Kaddami, and A. Ajji, Characterization of rheological and thermophysical properties of HDPE-wood composite. J. of Appl. Polym. Sci. 131 (13), (2014).

86. K. Wang, F. Addiego, A. Laachachi, B. Kaouache, N. Bahlouli, V. Toniazzo, et al. Dynamic behavior and flame retardancy of HDPE/hemp short fiber composites: Effect of coupling agent and fiber loading. Composite Structures 113 (1), 74-82 (2014).

87. C. Xiong, R. and Qi, Y, Wang, Wood-Thermoplastic Composites from Wood Flour and High-Density Polyethylene. J. of Appl. Polym. Sci. 114 (2), 1160-8(2009).

88. C. -y. Hwang, C. -y. Hse, and T. F. Shupe, Effects of raw materials on the properties of wood fiber-polyethylene composites - Part 3: Effect of a compatibilizer and wood adhesive on the interfacial adhesion of wood/plastic composites. Forest Products J. 58 (5), 66-72 (2008).

89. A. Kaboorani, Effects of Formulation Design on Thermal Properties of Wood/Thermoplastic Composites. J. of Comp. Mat. 44(18), 2205-15 (2010).

90. E. M. Fernandes, V. M. Correlo, J. F. Mano, and R. L. Reis, Polypropylenebased cork-polymer composites: Processing parameters and properties. Composites Part B: Engineering 66 (0), 210-23 (2014).

91. K. Oksman, and H. Lindberg, The influence of a SBS compatibilizer in polyethylene-wood flour composites. Holzforschung 52 (6), 661-6 (1998).

92. F. Carrasco, and P. Pages, Mechanical benefits of materials composed by high density polyethylene and cellulose fibres. Afinidad 52 (459), 327-34 (1995).

93. R. G. Raj, B. V. Kokta, Mechanical properties of surface modified cellulose fiber thermoplastic composites. Acs Symposium Series 476, 76-87 (1992).

94. Z. A. M. Ishak, A. Aminullah, H. Ismail, and H. D. Rozman, Effect of silanebased coupling agents and acrylic acid based compatibilizers on mechanical properties of oil palm empty fruit bunch filled high-density polyethylene composites. J. of Appl. Polym. Sci. 68 (13), 2189-203 (1998).

95. P. S. Razi, R. Portier, A. Raman, Studies on polymer-wood interface bonding: Effect of coupling agents and surface modification. J. of Comp. Mat. 33 (12), 1064-79 (1999).

96. M. Bengtsson, P. Gatenholm, and K. Oksman, The effect of crosslinking on the properties of polyethylene/wood flour composites. Comp. Sci. \& Tech. 65 (10), 1468-79 (2005).

97. M. Bengtsson, and K. Oksman, Silane crosslinked wood plastic composites: Processing and properties. Comp. Sci. \& Tech. 66 (13), 2177-86 (2006).

98. M. Abdelmouleh, S. Boufi, M. N. Belgacem, and A. Dufresne, Short naturalfibre reinforced polyethylene and natural rubber composites: Effect of silane coupling agents and fibres loading. Comp. Sci. \& Tech. 67 (7-8), 1627-39 (2007).

99. H. A. Youssef, M. R. Ismail, M. A. M. Ali, and A. H. Zahran, Effect of the various coupling agents on the mechanical and physical properties of thermoplastic-bagasse fiber composites. Polym. Comp. 29 (9), 1057-65 (2008). 
100. A. Rachini, G. Mougin, S. Delalande, J. Y. Charmeau, C. Barres, and E. Fleury, Hemp fibers/polypropylene composites by reactive compounding: Improvement of physical properties promoted by selective coupling chemistry. Polymer Degradation and Stability 97 (10), 1988-95 (2012).

101. K. L. Pickering, A. Abdalla, C. Ji, A. G. McDonald, and R. A. Franich, The effect of silane coupling agents on radiata pine fibre for use in thermoplastic matrix composites. Composites Part A-Applied Science and Manufacturing 34 (10), 915-26 (2003).

102. K. P. Mieck, A. Nechwatal, and C. Knobelsdorf, Fiber-matrix adhesion in composites of a thermoplastic matrix and flax .1. Pretreatment of flax fibres with silanes. Angewandte Makromolekulare Chemie 224, 73-88 (1995).

103. T. S. Hwang, K. S. Shin, J. T. Lee, and T. H. Yoon, Effect of coupling agent on the mechanical properties of wood-thermoplastic composites. PolymerKorea 23 (3), 450-5 (1999).

104. R. G. Raj, and B. V. Kokta, Thermochemical properties of polyethylene wood fiber composites. Acs Symposium Series 489, 99-117 (1992).

105. Y. Geng, and M. -P. G. Laborie, The Impact of Silane Chemistry Conditions on the Properties of Wood Plastic Composites with Low Density Polyethylene and High Wood Content. Polym. Comp. 31 (5), 897-905 (2010).

106. C. Xiong, R. Qi, and W. Gong, The preparation and properties of wood flour/ high density polyethylene composites by in-situ reaction extrusion. Polym. for Adv. Tech. 20 (3), 273-9 (2009).

107. J. Lu, R. Qi, X. Hu, Y. Luo, J. Jin, and P. Jiang, Preparation of soft wood-plastic composites. J. of Appl. Polym. Sci. 130(1), 39-46 (2013).

108. V. K. Thakur, M. K. Thakur, P. Raghavan, and M. R. Kessler, Progress in green polymer composites from lignin for multifunctional applications: A review. ACS Sustainable Chemistry and Engineering. 2 (5), 1072-92 (2014).

109. S. K. Samal, E. G. Fernandes, A. Corti, E. Chiellini, Bio-based PolyethyleneLignin Composites Containing a Pro-oxidant/Pro-degradant Additive: Preparation and Characterization. J. of Polym. and the Environ. 22 (1), 58-68 (2014).

110. H. D. Rozman, K. W. Tan, R. N. Kumar, A. Abubakar, Z. A. Mohd. Ishak, and H. Ismail, The effect of lignin as a compatibilizer on the physical properties of coconut fiber-polypropylene composites. European Polym. J. 36 (7), 1483-94 (2000).

111. D. Schorr, P. N. Diouf, and T. Stevanovic, Evaluation of industrial lignins for biocomposites production. Industrial Crops and Products 52 (0), 65-73 (2014).

112. E. M. Fernandes, I. Aroso, R. A. Pires, V. M. Correlo, P. Pitkäne, S. Koskimies, et al. Improvement on the mechanical properties of cork composites using suberin as coupling agent through a reactive extrusion process. Boston, MA2011.611-5.

113. L. Y. Mwaikambo, and M. P. Ansell, Chemical modification of hemp, sisal, jute, and kapok fibers by alkalization. J. of Appl. Polym. Sci. 84 (12), 2222-34 (2002). 
114. K. Joseph, S. Thomas, and C. Pavithran, Effect of chemical treatment on the tensile properties of short sisal fibre-reinforced polyethylene composites. Polymer 37 (23), 5139-49 (1996).

115. N. Lu, S. Oza, Tms. Thermal Properties of Hemp-High Density Polyethylene composites: Effect of two different chemical treatments (2012).

116. H. Wang, M. M. Kabir, and K. T. Lau, Hemp reinforced composites with alkalization and acetylation fibre treatments. Polymers and Polymer Composites 22 (3), 247-52 (2014).

117. M. M. Kabir, H. Wang, K. T. Lau, and F. Cardona, Chemical treatments on plant-based natural fibre reinforced polymer composites: An overview. Composites Part B-Engineering 43 (7), 2883-92 (2012).

118. Y. Xie, C. A. S. Hill, Z. Xiao, H. Militz, and C. Mai, Silane coupling agents used for natural fiber/polymer composites: A review. Composites Part A-Applied Science and Manufacturing 41 (7), 806-19 (2010).

119. Y. Seki, M. Sarikanat, and M. A. Ezan, Effect of siloxane treatment of jute fabric on the mechanical and thermal properties of jute/HDPE. J. of Reinforced Plastics and Composites 31 (15), 1009-16 (2012).

120. M. J. John, and R. D. Anandjiwala, Recent developments in chemical modification and characterization of natural fiber-reinforced composites. Polymer Composites 29 (2), 187-207 (2008).

121. R. G. Raj, and B. V. Kokta, Linear low-density polyethylene filled with silanecoated wood fibers. Acs Symposium Series 457, 102-13 (1991).

122. F. G. Torres, and M. L. Cubillas, Study of the interfacial properties of natural fibre reinforced polyethylene. Polymer Testing 24 (6), 694-8 (2005).

123. F. P. La Mantia, M. Morreale, Green composites: A brief review. Compos Part A-Appl S. 42 (6), 579-88 (2011).

124. G. Kalaprasad, B. Francis, S. Thomas, C. R. Kumar, C. Pavithran, G. Groeninckx, et al. Effect of fibre length and chemical modifications on the tensile properties of intimately mixed short sisal/glass hybrid fibre reinforced low density polyethylene composites. Polymer International. 53 (11), 1624-38 (2004).

125. N. E. Zafeiropoulos, 3 - Engineering the fibre-matrix interface in naturalfibre composites. In Properties and Performance of Natural-Fibre Composites. K. L. Pickering (Ed.) pp. 127-62, Woodhead Publishing (2008).

126. S. Sapieha, J. F. Pupo, and H. P. Schreiber, Thermal degradation of cellulosecontaining composites during processing. J. of Appl. Polym. Sci. 37 (1), 23340 (1989).

127. A. Kaboorani, M. Faezipour, and G. Ebrahimi, Feasibility of Using Heat Treated Wood in Wood/Thermoplastic Composites. J. of Reinforced Plastics and Composites 27(16-17),1689-99 (2008).

128. A. Kaboorani, and K. R. Englund, Water sorption and mechanical performance of preheated wood/thermoplastic composites. J. of Comp. Mat. 45 (13), 1423-33 (2011).

129. Y. Kusano, Atmospheric Pressure Plasma Processing for Polymer Adhesion: A Review. The J. of Adhesion 90 (9), 755-77 (2013). 
130. S. Mukhopadhyay, and R. Fangueiro, Physical Modification of Natural Fibers and Thermoplastic Films for Composites - A Review. J. of Thermoplastic Composite Mater. 22 (2), 135-62 (2009).

131. B. S. Gupta, and M. -P. G. Laborie, Surface activation and adhesion properties of wood-fiber reinforced thermoplastic composites. Journal of Adhesion 83 (11), 939-55 (2007).

132. J. Felix, P. Gatenholm, and H. P. Schreiber, Plasma modification of cellulose fibers: Effects on some polymer composite properties. J. of Appl. Polym. Sci. 51(2), 285-95 (1994).

133. N. Olaru, L. Olaru, G. H. Cobiliac, Plasma-modified wood fibers as fillers in polymeric materials. Romanian Journal of Physics 50(9-10), 1095-101 (2005).

134. ASTM D 3878-04a: Standard terminology for composite materials (2004).

135. A. Zolfaghari, A. H. Behravesh, E. Shakouri, E. Soury, Flow Balancing in Die Design of Wood Flour/HDPE Composite Extrusion Profiles with Consideration of Rheological Effect. Polym. Eng. and Sci. 50 (3), 543-9 (2010).

136. N. M. Stark, and L. M. Matuana Surface chemistry changes of weathered HDPE/wood-flour composites studied by XPS and FTIR spectroscopy. Polymer Degradation and Stability 86 (1), 1-9 (2004).

137. B. Tisserat, L. Reifschneider, N. Joshee, and V . L. Finkenstadt, Properties of High Density Polyethylene - Paulownia Wood Flour Composites via Injection Molding. Bioresources 8 (3), 4440-58 (2013).

138. S. Mohanty, and S. K. Nayak, Short Bamboo Fiber-reinforced HDPE Composites: Influence of Fiber Content and Modification on Strength of the Composite. J. of Reinforced Plastics and Composites 29 (14), 2199-210 (2010).

139. C. Grande, F. G. Torres, Investigation of fiber organization and damage during single screw extrusion of natural fiber reinforced thermoplastics. Advances in Polymer Technology 24 (2), 145-56 (2005).

140. R. H. López-Bañuelos, P. Ortega-Gudiño, R. M. Jiménez, R. González-Núñez, J. R. Robledo-Ortíz, Rotational molding of natural fibers and polyethylene composite materials. Society of Plastics Engineers (SPE) 3, (2012).

141. F. G. Torres, C. L. Aragon Final product testing of rotational moulded natural fibre-reinforced polyethylene. Polymer Testing. 25 (4), 568-77 (2006).

142. F. G. Torres, and R. M. Diaz, Morphological characterisation of natural fibre reinforced thermoplastics (NFRTP) processed by extrusion, compression and rotational moulding. Polymers \& Polymer Composites 12 (8), 705-18 (2004).

143. S. Panthapulakkal, and M. Sain, Agro-residue reinforced high-density polyethylene composites: Fiber characterization and analysis of composite properties. Composites Part A-Applied Science and Manufacturing 38 (6), 1445-54 (2007).

144. R. Chollakup, R. Tantatherdtam, S. Ujjin, and K. Sriroth, Pineapple Leaf Fiber Reinforced Thermoplastic Composites: Effects of Fiber Length and Fiber Content on Their Characteristics. J. of Appl. Polym. Sci. 119(4), 195260 (2011). 
145. F. Yao, Q. Wu, Coextruded polyethylene and wood-flour composite: Effect of shell thickness, wood loading, and core quality. J. of Appl. Polym. Sci. 118(6), 3594-601 (2010).

146. A. L. Leao, H. F. de Figueiredo Pupo, M. Z. Ferreira, and B. M. Cherian, Panels Produced from Thermoplastic Composites Reinforced with Peach Palm Fibers for Use in the Civil Construction and Furniture Industry. Molecular Crystals and Liquid Crystals 556, 246-53 (2012).

147. A. A. Pérez-Fonseca, J. R. Robledo-Ortíz, D. E. Ramirez-Arreola, P. OrtegaGudiño, D. Rodrigue, and R. González-Núñez, Effect of hybridization on the physical and mechanical properties of high density polyethylene-(pine/ agave) composites. Materials \& Design.

148. E. M. Fernandes, V. M. Correlo, J. F. Mano, and R. L. Reis, Novel cork-polymer composites reinforced with short natural coconut fibres: Effect of fibre loading and coupling agent addition. Composites Science and Technology 78, 56-62 (2013).

149. E. M. Fernandes, J. F. Mano, and R. L. Reis, Hybrid cork-polymer composites containing sisal fibre: Morphology, effect of the fibre treatment on the mechanical properties and tensile failure prediction. Composite Structures 105, 153-62 (2013).

150. E. M. Fernandes, I. M. Aroso, J. A. Covas, J. F. Mano, R. L. Reis, Functionalized cork-polymer composites (CPC) by reactive extrusion using suberin and lignin from cork as coupling agents. Composites Part B: Engineering, doi: 10.1016/j.compositesb.2014.07.028 (2014)

151. T. Kuboki, Y. H. Lee, C. B. Park, and M. Sain, Mechanical Properties and Foaming Behavior of Cellulose Fiber Reinforced High-Density Polyethylene Composites. Polymer Engineering and Science 49 (11), 2179-88 (2009).

152. A. Junior de Menezes, G. Siqueira, A. A. S. Curvelo, and A. Dufresne, Extrusion and characterization of functionalized cellulose whiskers reinforced polyethylene nanocomposites. Polymer 50 (19), 4552-63 (2009).

153. L. Yu, K. Dean, and L. Li, Polymer blends and composites from renewable resources. Progress in Polym. Sci. 31 (6), 576-602 (2006).

154. Q. Li, and L. M. Matuana, Foam extrusion of high density polyethylene/ wood-flour composites using chemical foaming agents. J. of Appl. Polym. Sci. 88 (14), 3139-50 (2003).

155. Y. Lei, Q. Wu, C. M. Clemons, F. Yao, and Y. Xu, Influence of nanoclay on properties of HDPE/wood composites. J. of Appl. Polym. Sci. 106 (6), 395866 (2007).

156. B. K. Deka, and T. K. Maji, Effect of $\mathrm{TiO}_{2}$ and nanoclay on the properties of wood polymer nanocomposite. Compos Part A-Appl S. 42 (12), 2117-25 (2011).

157. S. Sheshmani, A. Ashori, and Y. Hamzeh, Physical properties of polyethylene-wood fiber-clay nanocomposites. J. of Appl. Polym. Sci. 118 (6), 3255-9 (2010). 
158. J. Przybylinsky, D. Mancosh, M. Haubert, and J. Mitchell, Formation of multicolor thermoplastic composite for outdoor decking and railing, involves forming multi-colored composite material by adding colorant and fibers into polymer composite base material, and extruding composite material. Fiber Composites Llc (2008).

159. R. M. Rowell Challenges in biomass-thermoplastic composites. J. of Polym. \& the Environ. 15(4), 229-35 (2007).

160. T. Akbulut, N. Ayrilmis, T. Dundar, A. Durmus, R. H. White, and M. Teker, Effect of boron and phosphate compounds on thermal and fire properties of wood/HDPE composites. International Journal of polymers and Technologies 3 (2), 67-75 (2011).

161. G. -F. Wu, and M. Xu, Effects of Boron Compounds on the Mechanical and Fire Properties of Wood-chitosan and High-density Polyethylene Composites. Bioresources 9 (3), 4173-93 (2014).

162. T. Lundin, R. H. Falk, and C. Felton, Fps; Fps FPS. Accelerated weathering of natural fiber-thermoplastic composites: Effects of ultraviolet exposure on bending strength and stiffness (2002).

163. R . Pucciariello, V. Villani, C. Bonini, M. D’Auria, and T. Vetere, Physical properties of straw lignin-based polymer blends. Polymer 45(12), 4159-69 (2004).

164. P. Fei, B. Fei, Y. Yu, H. Xiong, and J. Tan, Thermal properties and crystallization behavior of bamboo fiber/high-density polyethylene composites: Nano$\mathrm{TiO}_{2}$ effects. J. of Appl. Polym. Sci. 131 (3), (2014).

165. D. E. Pendleton, T. A. Hoffard, T. Adcock, B. Woodward, and M. P. Wolcott, Durability of an extruded HDPE/wood composite. Forest Products Journal. 52 (6), 21-7 (2002).

166. A. Schirp, and M. P. Wolcott, Influence of fungal decay and moisture absorption on mechanical properties of extruded wood-plastic composites. Wood and Fiber Science 37 (4), 643-52 (2005).

167. J. L. Lopez, P. A. Cooper, and M. Sain, Evaluation of proposed test methods to determine decay resistance of natural fiber plastic composites. Forest Products Journal 55 (12), 95-9 (2005).

168. B. Kord, and S. K. Hosseinihashemi, Effect of fungal decay on the hygroscopic thickness swelling rate of lignocellulosic filler-polyolefin biocomposites. Mechanics of Composite Materials 49 (6), 691-8 (2014).

169. S. G. Bajwa, D. S. Bajwa, and G. Holt, Optimal Substitution of Cotton Burr and Linters in Thermoplastic Composites. Forest Products J. 59 (10), 40-6 (2009).

170. J. Qian, Preparation of wood-like mold composite material by premixing bamboo fiber, wood powder, low density polyethylene, polymer wax, thermoplastic plastic, ultra fine talc powder, styrene and methyl acrylate mixed monomer, and plastics. Changshu Fangta Coating Chem Co Ltd (2012).

171. A. K. Bledzki, A. Jaszkiewicz, M. Murr, and V. E. Sperber, Processing techniques for natural and wood-fibre composites. In Properties and performance 
of natural-fibre composites. K. Pickering (Ed.). Woodhead Publishing Series in Composites Science and Engineering $N^{\circ} 21$ (2008).

172. D. B. Dittenber, and H. V. S. GangaRao, Critical review of recent publications on use of natural composites in infrastructure. Compos Part A-Appl S. 43 (8), 1419-29 (2012).

173. H. Bouafif, A. Koubaa, P. Perre, A. Cloutier, and B. Riedl, Wood Particle/ High-Density Polyethylene Composites: Thermal Sensitivity and Nucleating Ability of Wood Particles. J. of Appl. Polym. Sci. 113 (1), 593-600 (2009).

174. K. Hanawalt, Natural fibre extrusion. Plastics, Additives and Compounding 4 (11), 22-5 (2002).

175. A. K. Bledzki, J. Gassan, and S. Theis, Wood-filled thermoplastic composites. Mechanics of Composite Materials 34 (6), 563-8 (1998).

176. R. Huang, X. Xu, S. Lee, Y. Zhang, B. -J. Kim, and Q. Wu, High Density Polyethylene Composites Reinforced with Hybrid Inorganic Fillers. Morphology, Mechanical and Thermal Expansion Performance Materials 6, 4122-38 (2013).

177. Q. Wu, K. Chi , Y. Wu, and S. Lee, Mechanical, thermal expansion, and flammability properties of co-extruded wood polymer composites with basalt fiber reinforced shells. Materials \& Design 60, 334-42 (2014).

178. B. -J. Kim, F. Yao, G. Han, Q. Wang, and Q. Wu, Mechanical and physical properties of core-shell structured wood plastic composites: Effect of shells with hybrid mineral and wood fillers. Composites Part B: Engineering 45(1), 1040-8 (2013).

179. N. M. Stark, and L. M. Matuana, Coating WPCs using co-extrusion to improve durability. Proceedings of conference for coating wood and wood composites: designing for durability. Seattle, WA2007. 1-12.

180. M. Xanthos, Reactive Extrusion: Principles and Practice. Hanser Publishers, 304, (1992).

181. W. Luo, Z. Wang, C. Yuan, Y. Wu, and Z. Tang, Reactive compatibilization of wood fibre/HDPE composites and its mechanism. Fuhe Cailiao Xuebao/Acta Materiae Compositae Sinica 31 (1), 125-32 (2014).

182. H. Gao, Q. -W. Wang, H. -G. Wang, and Y. -M. Song, Properties of Highly Filled Wood Fiber-Maleic Anhydride Grafted Thermoplastic Blends Composites. In Environment Materials and Environment Management Pts 1-32010. Z. Y. Du, X. B. Sun (Eds.) p. 1856-60.

183. V. Palaniyandi, and J. Simonsen, Effect of compatibilizers on the crystallization kinetics of cellulose-filled high density polyethylene. Composite Interfaces 14 (1), 73-83 (2007).

184. W. O. S. Doherty, P. Mousavioun, and C. M. Fellows, Value-adding to cellulosic ethanol: Lignin polymers. Industrial Crops and Products 33(2), 259-76 (2011).

185. A. V. Maldhure, A. R. Chaudhari, and J. Ekhe, Thermal and structural studies of polypropylene blended with esterified industrial waste lignin. J. of Thermal Analysis and Calorimetry 103 (2), 625-32 (2011). 
186. R. R. N. Sailaja, and M. V. Deepthi, Mechanical and thermal properties of compatibilized composites of polyethylene and esterified lignin. Materials \& Design 31 (9), 4369-79 (2010).

187. K. Levon, J. Huhtala, B. Malm, and J. J. Lindberg, Improvement of the thermal stabilization of polyethylene with lignosulphonate. Polymer 28 (5), 74550 (1987).

188. G. Phiri, M. C. Khoathane, and E. R. Sadiku, Effect of fibre loading on mechanical and thermal properties of sisal and kenaf fibre-reinforced injection moulded composites. J. of Reinforced Plastics and Composites 33 (3), 283-93 (2014).

189. M. P. Wolcott, Formulation and process development of flat-pressed woodpolyethylene composites. Forest Products J. 53 (9), 25-32 (2003).

190. Injection Molding Handbook. T. A. Osswald, L. S. Turng, P. J. Gramann (Eds.) Hanser Publishers, Munich (2001).

191. R. Brooks, 2.30 - Injection molding based techniques. In Comprehensive Composite Materials. A. Kelly, C. Zweben (Eds.) pp. 999-1028, Oxford, Pergamon (2000).

192. A. G. V. De Carvalho Neto, T. A. Ganzerli, A. L. Cardozo, S. L. Fávaro, A. G. B. Pereira, E. M. Girotto, et al. Development of composites based on recycled polyethylene/sugarcane bagasse fibers. Polymer Composites 35 (4), 768-74 (2014).

193. A. Schirp, F. Loge, S. Aust, P. Swarier, G. Turner, and M. Wolcott, Production and characterization of natural fiber-reinforced thermoplastic composites using wheat straw modified with the fungus Pleurotus ostreatus. J. of Appl. Polym. Sci. 102 (6), 5191-201 (2006).

194. F. Sliwa, N. -E. El Bounia, G. Marin, F. Charrier, F. Malet, A new generation of wood polymer composite with improved thermal stability. Polymer Degradation and Stability 97 (4), 496-503 (2012).

195. K. Jayaraman, R. Halliwell, Blending of natural fibres and thermoplastics by screwless extrusion. In Multi-Functional Materials and Structures, Pts 1 and 2. A. K. T. Lau, J. Lu, V. K. Varadan, F. K. Chang, J. P. Tu, P. M. Lam (Eds.) p. 1141-4 (2008).

196. H. Bouafif, A. Koubaa, P. Perre, and A. Cloutier, Effects of composite processing methods on wood particle development and length distribution: Consequences on mechanical properties of wood-thermoplastic composites. Wood and Fiber Science 42 (1), 62-70 (2010).

197. Z. Ortega, A. N. Benitez, M. D. Monzon, P. M. Hernandez, I. Angulo, and M. D. Marrero, Study of Banana Fiber as Reinforcement of Polyethylene Samples Made by Compression and Injection Molding. J. of Biobased Materials and Bioenergy 4 (2), 114-20 (2010).

198. A. K. Bledzki, and E SV. Recent developments and tendencies for natural fibre filled polymers. in Proceedings: 3rd International Workshop on Green Composites, 2005, Kyoto, Japan2005.

199. http://www.pallmannpulverizers.com/the_palltruder.htm. February 2014. 
200. K. Jayaraman, R. Lin, D. Bose, M. Maarouf, Natural fibre-reinforced thermoplastics processed by rotational moulding. In Advanced Materials and Processing Iv. D. Zhang, K. Pickering, B. Gabbitas, P. Cao, A. Langdon, R. Torrens, et al., (Eds.) p. 307-10, (2007).

201. D. Bhattacharyya, X. Yuan, and A. J. Easteal, Mechanical performance of rotomoulded wollastonite-reinforced polyethylene composites. International J. of Modern Physics B. 21 (07), 1059-66 (2007).

202. S. B. Tan, P. R. Hornsby, M. B. McAfee, M. P. Kearns, and M. P. McCourt, Internal cooling in rotational molding-A review. Polym Eng Sci. 51 (9), 1683-92 (2011).

203. F. G. Torres, M. Aguirre, Rotational moulding and powder processing of natural fibre reinforced thermoplastics. International Polymer Processing. 18 (2), 204-10 (2003).

204. J. E. Winandy, N. M. Stark, and C. M. Clemons, Considerations in recycling of wood-plastic composites. 5th Global Wood and Natural Fibre Composites Symposium. p. 1-9, Kassel, Germany (2004).

205. GreenCore. http://greencorenfccom/productshtm\#Applications.

206. Designers \& Builders of custom decks. http://wwwdeckspecialistscom/ compositedeckmaterialshtm.

207. B. Hunnicutt, Injection molding wood-plastic composites. Pastics Technology (2007)

208. W. M. Fender, T. Kelley, and V. W. Lee, Polymer composite, i.e. cellulose and thermoplastic composite e.g. high density polyethylene used as e.g. synthetic wood for decking industry, comprises chlorinated resin coupling aid, resin chlorinated to specific percentage. W. M. Fender, T. Kelley, V. W. Lee, Dover Chem Corp (2004).

209. S. S. Jong, and B. L. Seok, Method for manufacturing panel for finishing decoration of e.g. marble, involves making and extruding panel after mixing thermoplastic resin and inorganic fiber such that inorganic fiber reinforced plastics are manufactured. Lg Hausys Ltd (2011).

210. J. D. Muzzy, D. W. Holty, D. C. Eckman, and J. R. Stoll, Thermoplastic composite, used as blanks for compression molded parts, comprises recycled thermoplastic matrix and high modulus glass, natural, aramid or carbon fibers having preset minimum length and modulus. J. D. Muzzy, D. W. Holty, D. C. Eckman, J. R. Stoll, Georgia Composites (2001).

211. J. M. Warnes, and A. ernyhough, Plastic-fiber composite products/pellets used as feedstock in e.g. plastic manufacture, are obtained by breaking down lignocellulosic material or natural fiber, applying binder formulation and forming pellets or granules. New Zealand Forest Res Inst Ltd (2011).

212. H. Yin, Anti-static bamboo fiber mold composite material, comprises e.g. bamboo fiber, wood powder, low density polyethylene, thermoplastic resin, styrene and methyl acrylate mixed monomer, dibasic lead phosphate and dibasic lead stearic acid. Changshu Changfu Organic Composite Ferti (2012). 
213. E. Rodriguez Senin, P. M. Romero Romero, Composite material used for manufacturing interior automotive parts and furniture, comprises polyolefin as matrix polymer, where polyolefin is polyethylene or polypropylene, and polyethylene is high density polyethylene. Aimen Asoc Investigacion Metalurgicae (2011).

214. R. Li, Environmental degradation of wood-HDPE composite. Polymer Degradation and Stability 70 (2), 135-45 (2000).

215. B. Coburn, Decking Materials. 2013. http://actionplushiwordpresscom/ 2013/01/23/decking-materials/2013. 
